\title{
A systematic review and meta-analysis of dementia prevalence in seven developing countries: A STRiDE project
}

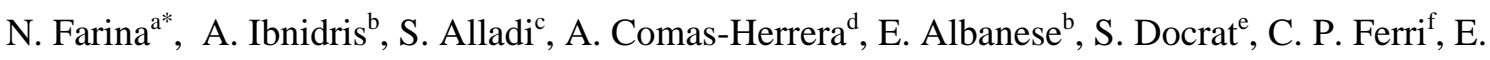 \\ Freeman $^{\mathrm{d}}$, I. Govia ${ }^{\mathrm{g}}$, R. Jacobs ${ }^{\mathrm{e}}$, C.I. Astudillo-Garcia ${ }^{\mathrm{h}}$, C. Musyimi ${ }^{\mathrm{i}}$, T.P. Sani ${ }^{\mathrm{j}}$, M. Schneider ${ }^{\mathrm{e}}$, I. \\ Theresia $^{\mathrm{j}}$, Y. Turana ${ }^{\mathrm{j}}, \mathrm{M} . \mathrm{Knapp}^{\mathrm{d}}$, S. Banerjee ${ }^{\mathrm{a}}$ on behalf of the STRiDE team.
}

${ }^{a}$ Centre for Dementia Studies, Brighton and Sussex Medical School, Brighton, UK;

${ }^{\mathrm{b}}$ Faculty of Biomedical Sciences, Università della Svizzera italiana, Lugano, Switzerland;

${ }^{c}$ National Institute of Mental Health and Neuro Sciences, Bengaluru, India;

${ }^{\mathrm{d}}$ London School of Economics, London, UK;

eUniversity of Cape Town, Cape Town, South Africa;

${ }^{\mathrm{f}}$ Universidade Federal de São Paulo, Department of Psychiatry, São Paulo, Brazil;

${ }^{g}$ Caribbean Institute for Health Research (CAIHR) - Epidemiology Research Unit, The University of the West Indies, Kingston, Jamaica;

h Servicios de Atención Psiquiátrica, Secretaría de Salud, México;

${ }^{i}$ Africa Mental Health Research and Training Foundation, Nairobi, Kenya.

${ }^{j}$ Atma Jaya Catholic University of Indonesia, Jakarta, Indonesia;

*Centre for Dementia Studies, Brighton and Sussex, Brighton, BN19RY. Email:

N.farina@bsms.ac.uk

This is an Accepted Manuscript of an article published by Taylor \& Francis in Global Public Health on 13/07/2020, available online: https://www.tandfonline.com/doi/

full/10.1080/17441692.2020.1792527 


\begin{abstract}
The STRiDE project sets out to support the development of effective dementia policy in middle-income countries. As part of this it will generate new data about the prevalence of dementia for a group of countries (Brazil, India, Indonesia, Jamaica, Kenya, Mexico, and South Africa). This study aims to identify the current estimates of dementia prevalence in these countries and where the gaps lie in the current literature. A systematic review was completed on 30th April 2019 across electronic databases, identifying dementia prevalence literature originating from any of the seven countries. Four hundred and twenty-nine records were identified following de-duplication; 28 studies met the inclusion criteria and were included in the systematic review. Pooled estimates of dementia prevalence ranged from $2 \%$ to $9 \%$ based on DSM-IV criteria; these figures were generally higher in studies using other diagnostic criteria (e.g. the 10/66 algorithm). Available prevalence data varied between countries. Only Brazil, Mexico and India had data derived from studies judged as having a low risk of bias. Irrespective of country, studies often were not explicit in detailing the representativeness of their sample, or whether there was non-response bias. Further transparent and externally valid dementia prevalence research is needed across the STRiDE countries.
\end{abstract}

Keywords: middle-income, diagnostic criteria, older adults 


\section{Introduction}

With population ageing, the number of people living with dementia is growing rapidly, especially in low- and middle-income countries (Prince, Guerchet, et al., 2013). Worldwide, an estimated 47 million people had dementia worldwide in 2015; this number is projected to increase to 66 million by 2030, and 131 million by 2050 (Prince et al., 2015). In low- and middle-income countries, the increase in numbers with dementia is happening within a context of health- and social-care systems that are generally unprepared for this challenge. Many low- and middle-income countries have very few data on dementia prevalence. One element of the STRiDE programme (STrengthening Responses to dementia In DEveloping countries, www.stride-dementia.org/) aims to fill this gap by generating new prevalence evidence in a subset of the seven STRiDE countries (Brazil, India, Indonesia, Jamaica, Kenya, Mexico, and South Africa). STRiDE is designed to support,perhaps to accelerate, the development of effective dementia policy and national planning in these seven countries, with the ultimate goal of improving dementia care, treatment and support systems so that people with dementia are able to live well. We chose the seven STRiDE counties on two criteria, the first was that they should represent a range of circumstances (population size, land mass sizes, different Gross Domestic Product sector compositions of agriculture, industry and service but all with $45 \%$ or higher reliance on the service sector) and needs, demonstrate different degrees of progress towards meeting the challenges presented by dementia, and are all on the list of Official Development Assistance (ODA) recipients. The second was pragmatic on the basis of existing research and policy links and willingness to participate.

Previous systematic reviews in this area tend to focus on single countries (e.g. Dong et al. 2007; Fagundes et al. 2011) or countries that are geographically close (e.g. Wu et al. 2013); this may prevent researchers from identifying patterns across developing countries. A notable exception is the World Alzheimer’s Report 2015 (Prince et al., 2015). The novelty of our review lies in its deep dive into the data available in the seven STRiDE countries, including focussed efforts to uncover a broader set of literature that may be more difficult to capture (e.g. inclusion of non-peer reviewed reports), whilst also being able to identify overarching themes between countries. Our primary aim was to obtain accurate, up-to-date estimates of dementia prevalence, in people aged over 60, across the seven STRiDE countries. We also aimed to appraise the design and methods of existing primary studies to formally assess their proneness to bias, so as to help design a harmonized STRiDE dementia prevalence study 
protocol. The review used a validated risk-of-bias instrument to identify strengths and weaknesses of previous studies.

\section{Methods}

This protocol was registered on PROSPERO (CRD42018089999) and adhered to the PRISMA guidelines.

\section{Eligibility Criteria}

We applied the inclusion and exclusion criteria originally used for the 2015 World Alzheimer’s Report (Prince et al., 2015), with some adaptations aimed at increasing inclusiveness. Most notably, our review included non-peer reviewed publications and allowed for a broader range of diagnostic criteria to be applied for detecting dementia, recognising that diagnostic criteria that require clinical training may be prohibitive in lowand middle-income countries.

\section{Inclusion Criteria}

- Population-based studies of the prevalence of dementia among people aged 60 years and over.

- No formal diagnostic standard was required, so long as it had face validity. For example, if the study did not use an internationally recognised diagnostic standard (e.g. DSM-IV), then the authors needed to provide evidence that the criteria used had the equivalent sensitivity and specificity. Face validity was determined first by reading the reported validity as presented by the identified full-texts, and then by reading any cited publications related to the diagnostic validity. If unclear about the validity based on the literature presented within the full-text, the research team would search for evidence of validity of the diagnostic tools, and discuss between the two researchers.

- Studies that independently reported data from at least one of the seven STRiDE countries. 


\section{Exclusion Criteria}

- Studies in which diagnosis of dementia depended on accessing dementia care services.

- Studies sampling from an out-of-date population (i.e., register compiled $>3$ years prior to data collection)

- Studies sampling from a specific care setting, or other unrepresentative healthcare population.

- Studies in which only the prevalence of specific dementia sub-types were reported.

- Studies restricted to young-onset dementia (<59 years old).

\section{Information Sources}

We used iterations of the syntax 'dementia AND (prevalence OR epidemiology)’ (below) to search relevant databases (PubMed, SCOPUS, PsychINFO, SciELO, and WoS) using a combination of MeSH terms and text words, and relevant synonyms, spelling variations, and acronyms as appropriate. To identify grey literature, we used electronic databases such as Opengrey.eu and Google Scholar, and we hand-searched the references of those relevant studies identified. We contacted experts in each country, who are also part of the broader STRiDE team, to check for omissions and unpublished data. These experts were asked to identify and forward any known dementia prevalence literature (peer-reviewed or not). Experts were not asked to apply any eligibility criteria, which was undertaken by two of the authors (NF and AI) during the study selection process.

We adopted a comprehensive lateral search strategy, in which we explored citations from identified articles, but also previous reviews that explored this topic, for example the World Alzheimer Report 2015 (Prince et al., 2015). We also explored citation searches using the "Cited by" option on Google Scholar, and the "Related articles” option in PubMed.

For potentially relevant conference proceedings we contacted the corresponding author (where possible) to obtain access to the original data and information when needed. In addition, corresponding authors were contacted to obtain full-texts where not available online, or through our academic library systems. 


\section{Search Strategy}

We adopted a broad yet specific search criteria, which we piloted before use. The search strategy included terms related to: 1) the health condition of interest (dementia), 2) Type of study (prevalence OR epidemiology) and 3) Countries of interest ("South Africa" OR Indonesia OR India OR Jamaica OR Mexico OR Brazil OR Kenya)

For the exact searches used for each database, see Appendix A.

\section{Study Records}

All search results were downloaded and entered into Mendeley, for automatic and manual deduplication. The de-duplicated list of studies was then uploaded to a web platform (https://rayyan.qcri.org/) (Ouzzani et al., 2016), which allowed for titles and abstracts to be screened by two researchers independently.

Google Translate was used to translate any non-English language text, with language assistance from members of the broader multi-lingual STRiDE team from each country as needed.

\section{Study Selection}

At the screening stage, two researchers (NF and AI) independently examined titles and abstracts to see if they met inclusion criteria. In any cases of uncertainty, we included the study in the full-text phase (below). We collected the full-texts of all potentially eligible studies, and the two reviewers (NF and $\mathrm{AI}$ ) independently established eligibility applying the full inclusion/exclusion criteria, tracking decisions using a pre-piloted form and dedicated table. During the shortlisting stage there was moderate agreement $(\kappa=0.79)$. Discrepant decisions were discussed between NF and AI; if no consensus was reached then it was resolved through discussion with two senior researchers (SB and EA). In situations where there were multiple full-texts related to a single study (e.g. same data set), an original full-text was selected to be the primary source of information.

\section{Data Abstraction}


Data, defined as any information about (or deriving from) a study, were extracted from the full-texts of each included study using two sets of purposively designed, pre-piloted tables of: study design; characteristics of study delivery; main and secondary results; risk of bias; and study quality assessment. The extracted data were entered into an existing tool (The Joanna Briggs Institute, 2014), with additional items added to allow extraction of elements relevant to assessing risk of bias and study methodology specific to dementia prevalence (number of phases, dementia diagnostic criteria etc.). As the purpose of this review was to gain insight into the current state of the literature, including reporting styles, no efforts were made to contact authors for supplementary materials or clarifications outside of what was reported.

\section{Data Items}

For unweighted prevalence, we extracted either:

1) numerator and denominator,

2) prevalence and denominator,

3) prevalence and standard error, or

4) prevalence and $95 \%$ confidence intervals.

For weighted prevalence we extracted either:

1) weighted prevalence and weighted standard error, or

2) weighted prevalence and weighted $95 \%$ confidence intervals.

Studies were presented in different formats, either as a whole sample, gender-stratified, agestratified, or a combination of them. We prioritised the extraction of whole sample raw prevalence data and extracted gender- and age-stratified prevalence data when available.

Descriptive information about the methodology and outcomes used in the included studies were extracted, such as sampling strategies, sample size, response rates and diagnostic criteria.

\section{Outcomes and Prioritisation}

The primary outcome of this systematic review was dementia prevalence.

\section{Risk of Bias in Individual Studies}


Risk of bias of the included studies was assessed using an existing tool for prevalence studies (Hoy et al., 2012). This has 10 domains, covering internal and external validity aspects of the studies. A single author (NF) judged each item (High vs Low Risk) based on predefined criteria. A second author (AI) reviewed the decisions, and any disagreements were discussed within the broader group. This tool was selected because it has been deemed as being easy to use, has good inter-rater agreement ( $\kappa=0.82$ ) (Hoy et al., 2012) and has been adopted in previous prevalence-related systematic reviews (e.g.(Lundorff et al., 2017; Stolwijk et al., 2016)).

As per the guidance of the tool, any studies in which there was insufficient information to permit a judgement on an item was deemed as high risk. The final risk-of-bias rating of each study was selected based on the sum of decisions of each item. As the final risk-of-bias score has little guidance, we devised an algorithm to guide the decision-making process. Additional evidence of bias (e.g. abnormal prevalence rates) could be used as rationale to change the final risk-of-bias score. The criteria were:

- High risk of bias - Three or more items $(\geq 75 \%)$ within the external validity domain OR four or more items $(\geq 75 \%)$ within the internal validity domain being judged as having a high risk of bias.

- Low risk of bias - Fewer than two items judged as high risk within the external validity domain AND fewer than three items judged as high risk within the internal validity domain.

- Moderate risk of bîas - All other scenarios.

The risk-of-bias toolwas used for descriptive purposes and to formally explore sources of heterogeneity across studies. It is important to highlight that the scores only reflect information reported in each record and may not reflect the actual risk of bias of a study. Due to the nature of the tool, shorter reports are likely to have higher bias.

\section{Summary Measures}

Dementia prevalence (and 95\% confidence intervals) was used as the summary measure.

\section{Data synthesis}


Descriptive data and risk of bias were reported for all included studies. A narrative synthesis of the findings was presented, grouped by country. Depending on the number of studies included in each country, data were synthesised using a series of meta-analyses to calculate pooled estimates of prevalence (double-arcsine) and 95\% confidence intervals (CIs) in each of the countries using random effects models. A complementary set of heterogeneity statistics (Cochran's Q, $\operatorname{tau}^{2}, \chi^{2}$ and $\mathrm{I}^{2}$ ) were reported between studies in each country where a metaanalysis was used (Higgins \& Thompson, 2002; Huedo-Medina et al., 2006). We used existing categorisation to guide the interpretation of the heterogeneity (i.e. $\mathrm{I}^{2}>75$ indicates high heterogeneity) (Higgins et al., 2003). No efforts were made to reduce the heterogeneity reported using exploratory statistics. However, efforts were made to split the meta-analyses into subgroups (e.g. based on diagnostic criteria) whilst also potential post hoc explanations for heterogeneity between studies were considered.

\section{Confidence in Cumulative Evidence}

There are no standardised or widely adopted tools to assess confidence in cumulative evidence in prevalence studies, and therefore we did not describe this.

\section{Results}

\section{Results of the search}

Our search was completed on $30^{\text {th }}$ April 2019. A total of 820 records were initially identified. Twenty-two records were also identified through lateral searches, and input from countryspecific researchers of the STRiDE team. Following de-duplication there were 461 records remaining. Following the screening of the abstract and title, 365 records were deemed to not have met the inclusion criteria. We were unable to access three records (two conference proceedings, one thesis). The full-texts of 93 records were screened (Figure 1).

\section{Included Studies}

A total of 30 studies (50 records) were included in this review. Seven studies were from Brazil, 16 from India, three from Mexico, two from Jamaica, and two from South Africa. (One study reported on multiple countries). There were no studies for Kenya or Indonesia that met the inclusion criteria. 
Across the included studies, DSM-IV (and DSM-IV TR) was the most commonly used for dementia diagnosis. The most frequently adopted study design was a two-phase survey: screening followed by diagnosis. Identifying outcome measures captured in each study was difficult, due to variations in reporting style. There is considerable variation in the types and detail of measures used. There was a general tendency to capture domains of cognition, neuropsychiatric symptoms and function. Personcentred outcomes (e.g. quality of life) and carer-related information were generally lacking across studies. Importantly, there was a lack of transparency on the language format of the questionnaires, and whether they had been cross-culturally adapted for use within their country-specific context. Full descriptive details of the studies and their methodologies are presented in Appendix B.

\section{Excluded Studies}

A total of 43 records were excluded. Records were most frequently excluded because they did not apply an appropriate diagnostic criterion for dementia $(n=15)$ or did not specifically report dementia prevalence data $(\mathrm{n}=8)$. See Appendix $\mathrm{C}$ for a list of excluded records.

Whilst there were a number of studies excluded from India, Brazil and Mexico, it is worth highlighting potentially relevant studies that did not meet our inclusion criteria from countries that are underrepresented in the literature more broadly (i.e. Kenya, Jamaica, Indonesia, and South Africa).

In Kenya, a monograph was identified which included the prevalence of dementia. However it was excluded because the authors used performance on a single cognitive instrument alone as a means to define dementia (Ndetei et al., 2013). This could account for why such a high percentage of the sample (44\%) had 'probable dementia' $(n=48)$ or a 'diagnosis of dementia' $(n=61)$. In a more recent report, 15.9\% ( $n=1,235)$ of participants were diagnosed with dementia (Mutiso, 2016); the report was excluded because it was unclear about the age of participants, how they were recruited, or what diagnostic criteria were utilised.

In Indonesia, a study (Hogervorst et al., 2011; Yesufu, 2009) was excluded because it appeared that the sampling frame was created 3 years prior to testing, whilst recruitment also seemed to be dependent on the sample having access to healthcare services. The authors reported that $4.1 \%$ of people over the age of 60 had possible dementia across urban and rural areas (Jakarta, Sumedang and Borobudur). Another study of people aged $\geq 60$ living in Yogyakarta found that $20.1 \%$ of people were diagnosed with dementia (Suriastini et al., 2017). This study was excluded because we judged the diagnostic criteria lacked face validity.

Finally, in South Africa, an older study identified that $8.6 \%$ of older adults in Cape Town had dementia (Ben-Arie et al., 1983). However, this study was excluded because dementia was defined 
solely by MMSE score and was deemed to be non-representative due to only recruiting a Coloured ${ }^{1}$ sample.

\section{Risk of Bias of Included Studies}

\section{External Validity}

The most frequent item judged as having high risk of bias was related to whether the study target population was a close representation to the national population. Nearly all studies were limited to a specific geographical area, commonly urban areas. Even when authors attempted to recruit from a representative sample, there was a lack of explicit evidence that the sample closely represented the national population. Only one study was judged as of low risk in relation to the close representation item (Eldemire-Shearer et al., 2018).

Many studies were judged to have a high risk of bias regarding how closely representative the sample frame was to the target population (Banerjee et al., 2008; Caramelli et al., 2009; de Jager et al., 2017; Jacob et al., 2007; Llibre Rodriguez et al., 2008; Neita et al., 2014; Seby et al., 2011; Shaji et al., 1996, 2005; Tiwari et al., 2013; Van Der Poel et al., 2011; Vas et al., 2001), with studies failing to clearly report how they chose their sampling frame or selecting a frame out of convenience. Nonresponse bias was also frequently judged to constitute a high risk of bias, due to authors either not stating the study response rate or, when the response rate was low $(<75 \%)$ whether there was any nonresponse bias (Banerjee et al., 2008, 2017; Bottino et al., 2008; Caramelli et al., 2009; Cesar et al., 2016; de Jager et al., 2017; Eldemire-Shearer et al., 2018; Gurukartick et al., 2016; Llibre Rodriguez et al., 2008; Lopes et al., 2012; Neita et al., 2014; Singh et al., 2008; Velazquez-Brizuela et al., 2014). For the random selection of participants within the frame, the majority of studies were judged to have a low risk of bias because either a census was utilised, or randomisation occurred.

\section{Internal Validity}

Internal validity items across the studies were generally judged as having low risk of bias. The numerator and denominator item were occasionally judged as having high risk of bias because the authors did not report numerators and denominators sufficiently within the records, or the studies lacked clarity about why numbers in tables were not consistent.

\section{Total}

\footnotetext{
${ }^{1}$ Coloureds is an official term to refer to a distinct ethnic group in South Africa.
} 
Across the studies, only six were deemed to have low risk of bias: two in Brazil (Herrera et al., 2002; Scazufca et al., 2008), three in India (Chandra et al., 1998; Das et al., 2006; Rajkumar \& Kumar, 1996), and one in Mexico (Cruz-Alcalá \& Vázquez Castellanos, 2002). Thirteen studies were judged to have moderate risk of bias, and 10 studies were judged to have high risk of bias overall. Both Jamaica and South Africa did not have any studies that were deemed as low risk of bias. The risk of bias assessments were upgraded to 'high risk' in several studies (Caramelli et al., 2009; Cesar et al., 2016; Magalhães et al., 2008) with a high prevalence of dementia in their sample (>15\%), indicating that these estimates would likely change with the addition of new data.

\section{Prevalence of dementia}

Reported below is the prevalence of dementia for each study split by country. Unless otherwise specified, prevalence rates are reported for samples aged $\geq 60$, based on DSM-IV diagnostic criteria.

\section{Brazil}

Seven studies from Brazil were included (Bottino et al., 2008; Caramelli et al., 2009; Cesar et al., 2016; Herrera et al., 2002; Lopes et al., 2012; Magalhães et al., 2008; Scazufca et al., 2008). Of the seven studies, five were conducted in the state of São Paulo.

Of the five studies in São Paulo state, four were urban and one urban and rural. The estimated dementia prevalence varied from across these. (i) Scazufca et al., (2008) reported 5.1\% (4.1-6.0) in those aged $\geq 65$ years old ( $\mathrm{n}=2072$ ); (ii) Lopes et al., (2012) reported 5.9\% (4.6-7.2) in Ribeirão Preto ( $\mathrm{n}=1145)$; (iii) Bottino et al (2008) reported 6.8\% (5.6-8.0) (n=1,563); and (iv) Herrera et al., (2002) reported 7.1\% (6.0-8.5) amongst 1,656 older adults ( $\geq 65$ years old) from the urban region of Catanduva. The study in urban and rural areas of Tremembé, Cesar et al (2016) reported an estimated prevalence of $17.5 \%$ (14.6-20.6) of older adults $(n=630)$. This higher prevalence could be due to the bias introduced by having a modest response rate of the initial sample (56.9\%).

From the two studies originating outside of São Paulo state, prevalence rates were substantially higher. In an urban and rural region of Caeté (Minas Gerais state), there was an estimated dementia prevalence of 27.5\% (24.1-31.1), albeit within a sample of older adults aged over 75 years old ( $n=639$ ) (Caramelli et al., 2009). In a rural area of Santo Estevão (Bahia state), there was an estimated prevalence of 49.6\% (45.0-54.1), using the CAMDEX tool (Magalhães et al., 2008). It was unclear whether this was in accordance with DSM-IV criteria.

Across the studies there was a pooled prevalence of 14.3\% (6.8-23.9). However there was evidence of substantial heterogeneity, $\mathrm{I}^{2}=99.14, \chi^{2} \mathrm{p}<0.001, \operatorname{tau}^{2}=0.10$. A large amount of heterogeneity was introduced through the diagnostic criteria used. Studies that used DSM-IV criteria had only moderate 
heterogeneity $\left(\mathrm{I}^{2}=64.6, \chi^{2} \mathrm{p}=0.04, \mathrm{tau}^{2}=0.001\right)$, and had a pooled prevalence of $6.2 \%$ (5.2-7.3). See Figure 2.

\section{India}

Fifteen studies were identified from India (Banerjee et al., 2008, 2017; Chandra et al., 1998; Das et al., 2006; Gurukartick et al., 2016; Jacob et al., 2007; Llibre Rodriguez et al., 2008; Mathuranath et al., 2010; Rajkumar \& Kumar, 1996; Seby et al., 2011; Shaji et al., 1996, 2005; Singh et al., 2008; Tiwari et al., 2013; Vas et al., 2001).

Generally, dementia prevalence was estimated in urban settings, with Kolkata being the most common setting. In one such study, 2,720 participants in the urban region of Kolkata were surveyed, with an estimated dementia prevalence of 1.3\% (0.9-1.7) (Banerjee et al., 2008). Similarly, 1.1\% of older adults ( $n=8,542)$ were reported to have a diagnosis of dementia in Kolkata (Banerjee et al., 2017). In another study within Kolkata, there was a prevalence of 0.8\% (0.6-1.1) in a sample of 5,430 older adults (Das et al., 2006). Outside of Kolkata, there have been several studies to explore the prevalence of dementia in other urban samples. Mathuranath and colleagues estimated the prevalence of dementia in Trivandrum $(n=2,422)$ at 3.8\% (Mathuranath et al., 2010). In Channai, an estimated prevalence of $2.7 \%$ was reported in those aged 65 and over ( $n=1300)$ (Rajkumar \& Kumar, 1996). However, a more recent study in Chennai $(n=1005)$ estimated prevalence at $0.9 \%(0.3-1.5)$ in those aged 65 and above using DSM-IV criteria, though it was substantially higher using the 10/66 algorithm with an estimate of 7.5\% (5.8-9.1) (Llibre Rodriguez et al., 2008). In Kochi, 2.9\% aged 65 years and above ( $\mathrm{n}=1934)$ were reported to be identified with having dementia (Shaji et al., 2005). In Mumbai, 6,041 older adults were surveyed, in which $1.6 \%$ were identified with having dementia (Vas et al., 2001). Whilst in an unnamed urban region in North Western India ( $n=1376)$, there was an estimated prevalence of 3.0\% (2.6-4.3) (Singh et al., 2008), though other data were unavailable as we were only able to access a conference proceeding. The only study to have a somewhat higher prevalence was reported in the urban region of Wanowarie Bazaar (Seby et al., 2011). For those $\geq 65$ years old, there was an estimated prevalence of $14.9 \%$. Methodologically, there is no clear reason why this would be the case, though it could be attributed to the limited sample size $(n=202)$ or the use of ICD-10 diagnostic criteria.

In the rural region of Tamil Nadu, there was an estimated prevalence of $0.8 \%(0.4-1.6)$ for those aged $\geq 65$ ( $\mathrm{n}=1,000)$ using the DSM-IV criteria, but was 10.6\% (8.8-12.7) using the education-adjusted 10/66 algorithm (Jacob et al., 2007). The AGECAT dementia prevalence rate was very high (63.47\%), though this was not discussed within the article. In a rural region of Ballabgarh, there was an estimated prevalence of $1.4 \%$ of those aged $\geq$ of 65 years old ( $n=2715)$ (Chandra et al., 1998). In the Lucknow district $2.8 \%$ of older adults $(n=2,146)$ were estimated to have dementia (Tiwari et al., 
2013). In the rural region of Villupuram District, there was an estimated prevalence of $3.1 \%$ in people 65 years old and above ( $\mathrm{n}=1,304)$ (Gurukartick et al., 2016). The rural region of Thiruvaniyoor Panchayath $(n=2,067)$ reported a prevalence of 3.2\% based on the DSM-III-R (Shaji et al., 1996), whilst in Thiruporur ( $\mathrm{n}=750$ ), 3.5\% of the same age group were reported to have dementia based on the AGECAT (Rajkumar \& Kumar, 1996).

The initial pooled prevalence was 4.4\% (2.2 -7.2), with evidence of substantial heterogeneity between studies $\left(\mathrm{I}^{2}=99.4\right.$, Cochran's $\left.\mathrm{Q}=2868.67, \chi^{2} \mathrm{p}=<0.0001, \mathrm{tau}^{2}=0.07\right)$. The diagnostic criteria appeared to contribute a portion of the heterogeneity reported. However, even within diagnostic criteria substantial heterogeneity was reported. Pooled prevalence ranged from 1.8\% (1.3-2.4) based on the DSM-IV criteria, to $17.0 \%(0.0-66.0)$ based on the AGECAT. See Figure 3 ,

\subsubsection{Indonesia}

There were no studies that met the inclusion criteria for this review. Please see "Excluded Studies".

\subsubsection{Jamaica}

Two prevalence studies were identified from Jamaica (Eldemire-Shearer et al., 2018; Neita et al., 2014).

Neita and colleagues carried out a community survey of 200 older adults from two urban areas in Kingston, Jamaica (Neita et al., 2014). Dementia was diagnosed in 6.5\% (3.4-10.4) based on DSM-IV criteria. In the study by Eldemire-Shearer and colleagues, a national survey of 2,782 people aged 60 years and above were recruited. A random sample of 301 participants (158 cases with MMSE $<20$, 143 controls with MMSE $>20$ ) were subsequently assessed for dementia using the DSM-IV. Based on the raw data $11.4 \%(8.0-15.3)$ of participants had a diagnosis of dementia. The authors also noted that applying the anticipated number of cases of dementia in each group to the whole sample $(n=2782)$, would yield a prevalence of 5.9\%.

There was a pooled prevalence of $8.8 \%$ (4.6-14.2). There was some indication of moderate heterogeneity between the two studies $\left(\mathrm{I}^{2}=70.78\right.$, Cochran's $\mathrm{Q}=3.42, \chi^{2} \mathrm{p}=0.06$, $\left.\operatorname{tau}^{2}=0.01\right)$. See Figure 4.

\subsubsection{Kenya}

There were no studies that met the inclusion criteria for this review. Please see "Excluded Studies". 


\subsubsection{Mexico}

Three studies were found to report dementia prevalence in Mexico (Cruz-Alcalá \& Vázquez Castellanos, 2002; Llibre Rodriguez et al., 2008; Velazquez-Brizuela et al., 2014).

Within the urban region of Guadalajara, 9.5\% (7.9-11.3) of people were diagnosed with dementia (Velazquez-Brizuela et al., 2014). In the 10/66 study (Llibre Rodriguez et al., 2008), participants aged 65 years and above were recruited from an urban $(n=1,002)$ area of Mexico, with a dementia prevalence of 4.1\% (2.8-5.3) using the DSM-IV criteria, and 8.6\% (6.8-10.4) using the 10/66 algorithm. The only data derived from a rural area also came from the 10/66 study (Llibre Rodriguez et al., 2008), in which 2.2\% (1.3-3.1) of the sample aged 65 years and above $(n=1,000)$ were diagnosed with dementia based on the DSM-IV, but an estimated prevalence of $8.5 \%$ (6.7-10.3) using the 10/66 algorithm. A study from the urban region of Tepatitlan reported a prevalence of $0.33 \%$, however this was across all ages of a larger cohort $(\mathrm{n}=9082)$, which did not provide a breakdown of these data (Cruz-Alcalá \& Vázquez Castellanos, 2002). Due to insufficient information in this study did not be included in the pooled meta-analysis.

Overall the pooled DSM-IV prevalence was 4.7\% (1.2-9.5), with evidence of substantial heterogeneity between studies ( $I^{2}=96.70$, Cochran's $Q=60.53, X^{2} \mathrm{p}<0.001$, tau $\left.{ }^{2}=0.03\right)$. Whilst pooled 10/66 algorithm prevalence was 8.4\% (7.4-9.9). See Figure 5.

\subsubsection{South Africa}

Two studies from South Africa were included in this review (de Jager et al., 2017; Van Der Poel et al., 2011). In the first study of 205 older adults ( $\geq 65$ years) from central South Africa, authors identified a dementia prevalence of $6.4 \%$ using DSM-IV criteria. We were unable to extract numerators or denominators for the whole sample, or split by gender, age or combination of both. Similarly, the authors reported that the prevalence of dementia according to the 10/66 algorithm was "unusually high”. The authors were unable to provide additional data at this stage.

In the second study (de Jager et al., 2017), 1,382 Xhosa-speaking community-dwelling older adults ( $\geq$ 60 years) were recruited from three catchment areas in an unnamed location within the Eastern Cape. The authors estimated that 7.6\% (6.3-9.1) of participants had dementia, using the 10/66 short diagnostic schedule.

\section{Discussion}


This systematic review set out to understand the prevalence of dementia across the seven STRiDE countries and the methodologies used to generate this evidence. Whilst there were no eligible studies from Indonesia and Kenya, 28 studies spanned the remaining STRiDE countries. India and Brazil had the largest number of studies included in this review.

Pooled meta-analyses within each country, based on DSM-IV, revealed that dementia prevalence rates ranged from 2\% (India) to 9\% (Jamaica). This is in line with global estimates of dementia, sitting at 5.2\% (Prince et al., 2015). Due to the general absence of included studies and data outside of India, we did not pursue meta-analysis split by other potential factors (age, gender or setting). It is likely that splitting the meta-analysis based on these factors would reduce some heterogeneity observed between studies, and that more heterogeneity might exist due to variation in study design, outcomes and diagnostic criteria. It should be noted that four studies introduced sizable heterogeneity into the metaanalyses, due to having small sample sizes and high prevalence rates (Caramelli et al,, 2009; Cesar et al., 2016; Magalhães et al., 2008; Seby et al., 2011). Two of these studies (Magalhães et al., 2008; Seby et al., 2011) fell short of a sample size needed to estimate a true prevalence of $6 \%$ with a precision of $\pm 2.1 \%$ (Prince et al., 2015).

The quality of studies included in this review was mixed, with a fifth (6/28) being judged as having a low risk of bias overall. Bias was commonly introduced through potential issues in external validity. Notably, the majority of studies adopted sampling techniques that minimise bias (e.g. random cluster sampling, all sectors within region, representative sectors); however, the authors did not explicitly state how representative their sampling frame was compared to the national picture. For example, prevalence studies in Brazil predominately originated in the southeast of the country. Another common item judged to have high risk of bias was the presence of non-response bias. Non-response can introduce a source of variation, and limit the representativeness of findings, with the reason for non-response (refusal, death/illness, moving home) affecting the characteristics and estimated prevalence of these non-response groups (Boersma et al., 2015). This could particularly be an issue in multiphase designs, as it can lead to underestimation of the prevalence of dementia and overestimation of precision (Prince, Bryce, et al., 2013). Two phase designs were most commonly adopted in studies included within this systematic review. Whilst language of diagnostic assessments was not of particular focus in this systematic review, it is also important to highlight the countries where language is strongly associated with specific ethnicities or regions, language may indirectly impact sample representativeness.

For inclusion in this review, studies were required to have a diagnostic criterion with face validity (consensus amongst authors). As such, there were a number of studies that were excluded because they used single cognitive impairment and/or functional tools to diagnose dementia. Among the included studies, DSM-IV criteria were frequently used to make a dementia diagnosis, which was 
reliant on hiring clinicians or utilising the CAMDEX toolkit. Within countries where a variety of diagnostic criteria were utilised, there was evidence that this introduced heterogeneity into the findings. This was evident in studies derived from the 10/66 group (Jacob et al., 2007; Llibre Rodriguez et al., 2008; Van Der Poel et al., 2011) which adopted multiple diagnostic criteria, and therefore produced multiple dementia prevalence rates. For example, the AGECAT estimated a prevalence of $63.4 \%$, the $10 / 66$ algorithm (education-adjusted) estimated dementia prevalence at $10.6 \%$, whilst the DSM-IV prevalence was $0.8 \%$ (Jacob et al., 2007). It is evident that diagnostic criteria employed are important determinants of prevalence estimates.

It should be noted that for a single study (de Jager et al. 2017) there was some discussion about its inclusion based on the diagnostic criteria used - the short version 10/66 algorithm. Despite being a relatively new diagnostic algorithm, recent evidence supports its validity across a number of settings (Abdin et al., 2017; Bernardo Seinhart et al., 2016; Stewart et al., 2016). For example, the short version 10/66 algorithm shows substantial agreement with clinical diagnosis of dementia (kappa = 0.70, AUC = 0.87) (Abdin et al., 2017). However, similar to the full 10/66 algorithm, the short version tends to estimate a higher rate of prevalence compared to the DSM-IV, which could be due to the DSM-IV dementia criterion underestimating dementia prevalence (Prince, 2009). Whilst the short version 10/66 algorithm (and the brief CSID from which it is derived) may appear to be less comprehensive compared to other methods for identifying dementia, it is important to recognise that there is an important place for algorithms that are both less time-intensive and do not require clinical training to administer.

A strength of this review was that we were able to capture all but two studies reported in the World Alzheimer's Report 2015 (Prince et al., 2015) despite having slightly different inclusion and exclusion criteria. We were also able to identify an additional 15 studies that were not identified in the World Alzheimer's Report 2015, partly because the search was more recent, but also because we enquired directly for studies within each country. This review is, however, limited in that it only covers the seven STRiDE countries, which prevents us making conclusions regarding the literature in other MICs. As highlighted within the section on risk of bias, another limitation of this systematic review is that it reflects data and information published (though not necessarily peer-reviewed), and therefore it may be that additional detail may exist but was not explicitly reported within the identified records.

\section{Conclusions}

There is substantial evidence of variability in terms of methodologies used to estimate dementia prevalence, making prevalence rates difficult to compare within and between countries. There is also 
wide variation within and between the countries in terms of risk of bias introduced by study designs (or how they are reported).

\section{Acknowledgements}

Thank you to all the members of the STRiDE teams who helped identify literature relating to this topic.

The research is funded by the Research Council UK (RCUK) through its Global Research Challenges Fund. The funders had no direct input into the formulation or creation of the protocol, or the results and their interpretation. 


\section{References}

Abdin, E., Vaingankar, J. A., Picco, L., Chua, B. Y., Prince, M., Chong, S. A., \&

Subramaniam, M. (2017). Validation of the short version of the 10/66 dementia diagnosis in multiethnic Asian older adults in Singapore. BMC Geriatrics, 17(1), 94.

Banerjee, T. K., Dutta, S., Das, S., Ghosal, M., Ray, B. K., Biswas, A., Hazra, A., Chaudhuri, A., Paul, N., \& Das, S. K. (2017). Epidemiology of dementia and its burden in the city of Kolkata, India. International Journal of Geriatric Psychiatry, 32(6), 605-614. https://doi.org/10.1002/gps.4499

Banerjee, T. K., Mukherjee, C. S., Dutt, A., Shekhar, A., \& Hazra, A. (2008). Cognitive Dysfunction in an Urban Indian Population - Some Observations. Neuroepidemiology; Basel, 31(2), 109-114.

Ben-Arie, O., Swartz, L., Teggin, A. F., \& Elk, R. (1983). The coloured elderly in Cape Town--a psychosocial, psychiatric and medical community survey. Part II. Prevalence of psychiatric disorders. South African Medical Journal = Suid-Afrikaanse Tydskrif Vir Geneeskunde, 64(27), 1056-1061.

Bernardo Seinhart, D., Castro, D., Borgioli, D., Guelar, V., Noemi Sanchez, V., Vicario, A., Perez Leguizamon, P., Pawluk, M., Del Sueldo, R., del Sueldo, M., Ines De Azkue, M., \& Taragano, F. (2016). Validation of the brief version of the community screening instrument for dementia (CSID) in a rural population in Argentina. Alzheimer's \& Dementia, 12, P765P766. https://doi.org/10.1016/j.jalz.2016.06.1455

Boersma, P., van Weert, J. C. M., Lakerveld, J., \& Droes, R.-M. (2015). The art of successful implementation of psychosocial interventions in residential dementia care: a systematic review of the literature based on the RE-AIM framework. International Psychogeriatrics / IPA, 27(1). https://doi.org/10.1017/S1041610214001409

Bottino, C. M. C., Azevedo, D., Tatsch, M., Hototian, S. R., Moscoso, M. A., Folquitto, J., Scalco, A. Z., Bazzarella, M. C., Lopes, M. A., \& Litvoc, J. (2008). Estimate of dementia prevalence in a community sample from São Paulo, Brazil. Dementia and Geriatric Cognitive Disorders, 26(4), 291-299. https://doi.org/10.1159/000161053

Caramelli, P., Teixeira, A. L., Barbosa, M. T., Santos, A. P., Pellizzaro, M., Guimarães, H. C., Beato, R. G., Carlos, B. M.J., Marra, H., \& Santos, E. L. (2009). Prevalence of cognitive impairment and dementia in a cohort of oldest old in Brazil: The Pietà study. Alzheimer's \& Dementia: The Journal of the Alzheimer's Association, 5(4), P391-P392.

Cesar, K. G., Brucki, S. M., Takada, L. T., Nascimento, L. F., Gomes, C. M., Almeida, M. C., Oliveira, M. O., Porto, F. H., Senaha, M. L., \& Bahia, V. S. (2016). Prevalence of cognitive impairment without dementia and dementia in Tremembé, Brazil. Alzheimer Disease \& Associated Disorders, 30(3), 264-271.

Chandra, V., Ganguli, M., Pandav, R., Johnston, J., Belle, S., \& DeKosky, S. T. (1998). Prevalence of Alzheimer's disease and other dementias in rural India: the Indo-US study. Neurology, 51(4), 1000-1008.

Cruz-Alcalá, L. E., \& Vázquez Castellanos, J. L. (2002). Prevalencia de algunas enfermedades neurológicas en la Ciudad de Tepatitlán, Jalisco, México. Rev Mex Neuroci, 3(2), 71-76.

Das, S. K., Biswas, A., Roy, T., Banerjee, T. K., Mukherjee, C. S., Raut, D. K., \& Chaudhuri, A. (2006). A random sample survey for prevalence of major neurological disorders in Kolkata. The Indian Journal of Medical Research, 124(2), 163-172. de Jager, C. A., Msemburi, W., Pepper, K., \& Combrinck, M. I. (2017). Dementia Prevalence in a Rural Region of South Africa: A Cross-Sectional Community Study. Journal of Alzheimer's Disease, 60(3), 1087-1096.

Dong, M., Peng, B., Lin, X., Zhao, J., Zhou, Y., \& Wang, R. (2007). The prevalence of 
dementia in the People's Republic of China: a systematic analysis of 1980-2004 studies. Age and Ageing, 36(6), 619-624. https://doi.org/10.1093/ageing/afm128

Eldemire-Shearer, D., James, K., Johnson, P., Gibson, R., \& Willie-Tyndale, D. (2018). Dementia among Older Persons in Jamaica: Prevalence and Policy Implications. West Indian Medical Journal. https://doi.org/10.7727/wimj.2017.133

Fagundes, S. D., Silva, M. T., Thees, M. F. R. S., \& Pereira, M. G. (2011). Prevalence of dementia among elderly Brazilians: a systematic review. Sao Paulo Medical Journal, 129(1), 46-50. https://doi.org/10.1590/S1516-31802011000100009

Gurukartick, J., Dongre, A. R., \& Shah, D. (2016). Social Determinants of Dementia and Caregivers' Perspectives in the Field Practice Villages of Rural Health Training Centre, Thiruvennainallur. Indian Journal of Palliative Care, 22(1), 25-32.

Herrera, E., Caramelli, P., Silveira, A. S. B., \& Nitrini, R. (2002). Epidemiologic survey of dementia in a community-dwelling Brazilian population. Alzheimer Disease and Associated Disorders, 16(2), 103-108.

Higgins, J. P., \& Thompson, S. G. (2002). Quantifying heterogeneity in a meta-analysis. Statistics in Medicine, 21(11), 1539-1558.

Higgins, J. P., Thompson, S. G., Deeks, J. J., \& Altman, D. G. (2003). Measuring inconsistency in meta-analyses. BMJ : British Medical Journal, 327(7414), 557-560.

Hogervorst, E., Mursjid, F., Ismail, R. I., Prasetyo, S., Nasrun, M., Mochtar, Ninuk, T., Bandelow, S., Subarkah, Kusdhany, L., \& Rahardjo, T. B. W. (2011). Validation of two short dementia screening tests in Indonesia. In Vascular Dementia: Risk Factors, Diagnosis and Treatment (pp. 235-256). https://www.scopus.com/inward/record.uri?eid=2-s2.084892022332\&partnerID=40\&md5=6fe322fdedf9ef6f746f642b857e09a2 Hoy, D., Brooks, P., Woolf, A., Blyth, F., March, L., Bain, C., Baker, P., Smith, E., \& Buchbinder, R. (2012). Assessing risk of bias in prevalence studies: modification of an existing tool and evidence of interrater agreement. Journal of Clinical Epidemiology, 65(9), 934-939. https://doi.org/10.1016/j.jclinepi.2011.11.014

Huedo-Medina, T. B., Sánchez-Meca, J., Marín-Martínez, F., \& Botella, J. (2006). Assessing heterogeneity in meta-analysis: Q statistic or I\$^2\$ index? Psychological Methods, 11(2), 193.

Jacob, K. S., Kumar, P. S., Gayathri, K., Abraham, S., \& Prince, M. J. (2007). The diagnosis of dementia in the community. International Psychogeriatrics, 19(4), 669-678.

Llibre Rodriguez, J. J., Ferri, C. P., Acosta, D., Guerra, M., Huang, Y., Jacob, K. S., Krishnamoorthy, E. S., Salas, A., Sosa, A. L., Acosta, I., Dewey, M. E., Gaona, C., Jotheeswaran, A. T., Li, S., Rodriguez, D., Rodriguez, G., Kumar, P. S., Valhuerdi, A., Prince, M., \& 10/66 Dementia Research Group. (2008). Prevalence of dementia in Latin America, India, and China: a population-based cross-sectional survey. Lancet (London, England), 372(9637), 464-474. https://doi.org/10.1016/S0140-6736(08)61002-8

Lopes, M. A., Ferrioli, E., Nakano, E. Y., Litvoc, J., \& Bottino, C. M. C. (2012). High prevalence of dementia in a community-based survey of older people from Brazil: association with intellectual activity rather than education. Journal of Alzheimer's Disease: JAD, 32(2), 307-316. https://doi.org/10.3233/JAD-2012-120847

Lundorff, M., Holmgren, H., Zachariae, R., Farver-Vestergaard, I., \& O’Connor, M. (2017). Prevalence of prolonged grief disorder in adult bereavement: A systematic review and metaanalysis. Journal of Affective Disorders, 212, 138-149.

https://doi.org/10.1016/j.jad.2017.01.030

Magalhães, M. O. de C., Peixoto, J. M. de S., Frank, M. H., Gomes, I., Rodrigues, B. M., Menezes, C., Cardoso, E., Carvalho, F., Aras, R., \& Melo, A. (2008). Risk factors for dementia in a rural area of Northeastern Brazil. Arquivos de Neuro-Psiquiatria, 66(2A), 157162. https://doi.org/10.1590/S0004-282X2008000200003 
Mathuranath, P. S., Cherian, P. J., Mathew, R., Kumar, S., George, A., Alexander, A., Ranjith, N., \& Sarma, P. S. (2010). Dementia in Kerala, South India: prevalence and influence of age, education and gender. International Journal of Geriatric Psychiatry, 25(3), 290-297.

Mutiso, V. (2016). Multi-sectoral Stakeholder TEAM Approach to Scale-Up Community Mental Health in Kenya (TEAM). Africa Mental Health Foundation.

Ndetei, D. M., Khasakhala, L., Kuria, M. W., Mutiso, V., Muriungi, S., \& Bagaka, B. (2013). A study on assessment of needs, care in the homes and clinical trends among the elderly in Kenya [A Rapid Situation Assessment]. Africa Mental Health Foundation.

Neita, S. M., Abel, W. D., Eldemire-Shearer, D., James, K., \& Gibson, R. C. (2014). The prevalence and associated demographic factors of dementia from a cross-sectional community survey in Kingston, Jamaica. International Journal of Geriatric Psychiatry, 29(1), 103-105. https://doi.org/10.1002/gps.3982

Ouzzani, M., Hammady, H., Fedorowicz, Z., \& Elmagarmid, A. (2016). Rayyan-a web and mobile app for systematic reviews. Systematic Reviews, 5. https://doi.org/10.1186/s13643016-0384-4

Prince, M. (2009). The 10/66 dementia research group - 10 years on. Indian Journal of Psychiatry, 51, S8-S15.

Prince, M., Bryce, R., Albanese, E., Wimo, A., Ribeiro, W., \& Ferri, C. P. (2013). The global prevalence of dementia: A systematic review and metaanalysis. Alzheimer's \& Dementia, 9(1), 63-75.e2. https://doi.org/10.1016/j.jalz.2012.11.007

Prince, M., Guerchet, M., Prina, M., \& Alzheimer's Disease International. (2013). The Global Impact of Dementia 2013-2050. Alzheimer's Disease International.

Prince, M., Wimo, A., Guerchet, M., Ali, G.-C., Wu, Y.-T., \& Prina, M. (2015). World Alzheimer Report 2015: The Global Impact of Dementia. Alzheimer's Disease International. https://www.alz.co.uk/research/world-report-2015

Rajkumar, S., \& Kumar, S. (1996). Prevalence of Dementia in the Community: a RuralUrban Comparison from Madras, India. Australasian Journal on Ageing, 15(2), 57-61.

Scazufca, M., Menezes, P. R., Vallada, H.P., Crepaldi, A. L., Pastor-Valero, M., Coutinho, L. M. S., Di Rienzo, V. D., \& Almeida, O. P. (2008). High prevalence of dementia among older adults from poor socioeconomic backgrounds in São Paulo, Brazil. International Psychogeriatrics, 20(2), 394-405. https://doi.org/10.1017/S1041610207005625

Seby, K., Chaudhury, S., \& Chakraborty, R. (2011). Prevalence of psychiatric and physical morbidity in an urban geriatric population. Indian Journal of Psychiatry, 53(2), 121.

Shaji, S., Bose, S., \& Verghese, A. (2005). Prevalence of dementia in an urban population in Kerala, India. The British Journal of Psychiatry: The Journal of Mental Science, 186, 136140. https://doi.org/10.1192/bjp.186.2.136

Shaji, S., Promodu, K., Abraham, T., Roy, K. J., \& Verghese, A. (1996). An epidemiological study of dementia in a rural community in Kerala, India. The British Journal of Psychiatry:

The Journal of Mental Science, 168(6), 745-749.

Singh, V. B., Kumar, P., Sameja, P., Devraja, R., Tundwal, V. K., \& Khatoon, N. (2008). ICP1-056: Prevalence of dementia in urban population of Northwest India. Alzheimer's \& Dementia: The Journal of the Alzheimer's Association, 4(4), T30-T31.

Stewart, R., Guerchet, M., \& Prince, M. (2016). Development of a brief assessment and algorithm for ascertaining dementia in low-income and middle-income countries: The 10/66 short dementia diagnostic schedule. BMJ Open, 6(5).

https://www.scopus.com/inward/record.uri?eid=2-s2.0-

84971276024\&doi=10.1136\%2Fbmjopen-2015-

010712\&partnerID=40\&md5=e62e8daac7bd70d8ba4c3186162ddba2

Stolwijk, C., Onna, M. van, Boonen, A., \& Tubergen, A. van. (2016). Global Prevalence of 
Spondyloarthritis: A Systematic Review and Meta-Regression Analysis. Arthritis Care \& Research, 68(9), 1320-1331. https://doi.org/10.1002/acr.22831

Suriastini, N. W., Turana, Y., Witoelar, F., Sikoki, B., Wicaksono, T., \& Dwi M, E. (2017). The Prevalence, Risk Factors of Dementia and Caregiver Knowledge of The Early

Symptoms : Evidence from a large-scale survey in Yogyakarta. IUSSP - 2017 International Population Conference. https://iussp.confex.com/iussp/ipc2017/meetingapp.cgi/Paper/4311 The Joanna Briggs Institute. (2014). The Joanna Briggs Institute Reviewers’ Manual 2014. The Systematic Review of Prevalence and Incidence Data. Adelaide, SA: The Joanna Briggs Institute.

Tiwari, S. C., Srivastava, G., Tripathi, R. K., Pandey, N. M., Agarwal, G. G., Pandey, S., \& Tiwari, S. (2013). Prevalence of psychiatric morbidity amongst the community dwelling rural older adults in northern India. The Indian Journal of Medical Research, 138(4), 504-514. Van Der Poel, R., Heyns, M., \& Gudeva-Nikovska, D. (2011). Prevalence of dementia in central South Africa. Program and Abstracts of the 26th International Conference of Alzheimer's Disease International.

Vas, C. J., Pinto, C., Panikker, D., Noronha, S., Deshpande, N., Kulkarni, L., \& Sachdeva, S. (2001). Prevalence of Dementia in an Urban Indian Population. International

Psychogeriatrics, 13(4), 439-450. https://doi.org/10.1017/S1041610201007852

Velazquez-Brizuela, I. E., Ortiz, G. G., Ventura-Castro, L., Arias-Merino, E. D., PachecoMoises, F. P., Macias-Islas, M. A., Velázquez-Brizuela, I. E., Ortiz, G. G., Ventura-Castro, L., Árias-Merino, E. D., Pacheco-Moisés, F. P., \& Macías-Islas, M. A. (2014). Prevalence of dementia, emotional state and physical performance among older adults in the metropolitan area of guadalajara, Jalisco, Mexico. Current Gerontology and Geriatrics Research, 2014, 387528-387528.

Wu, Y.-T., Lee, H., Norton, S., Chen, C., Chen, H., He, C., Fleming, J., Matthews, F. E., \& Brayne, C. (2013). Prevalence Studies of Dementia in Mainland China, Hong Kong and Taiwan: A Systematic Review and Meta-Analysis. PLOS ONE, 8(6), e66252. https://doi.org/10.1371/journal.pone.0066252

Yesufu, A. (2009). Demographic and modifiable risk factors for age related cognitive impairment and possible dementia [Thesis, Loughborough University].

https://dspace.lboro.ac.uk/dspace-jspui/handle/2134/32641

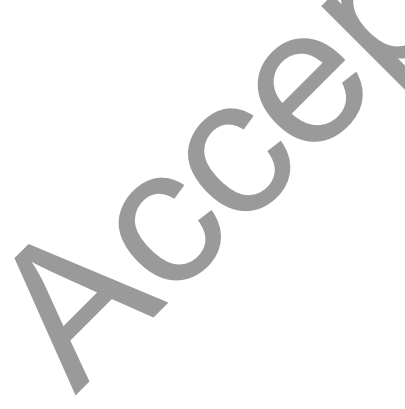



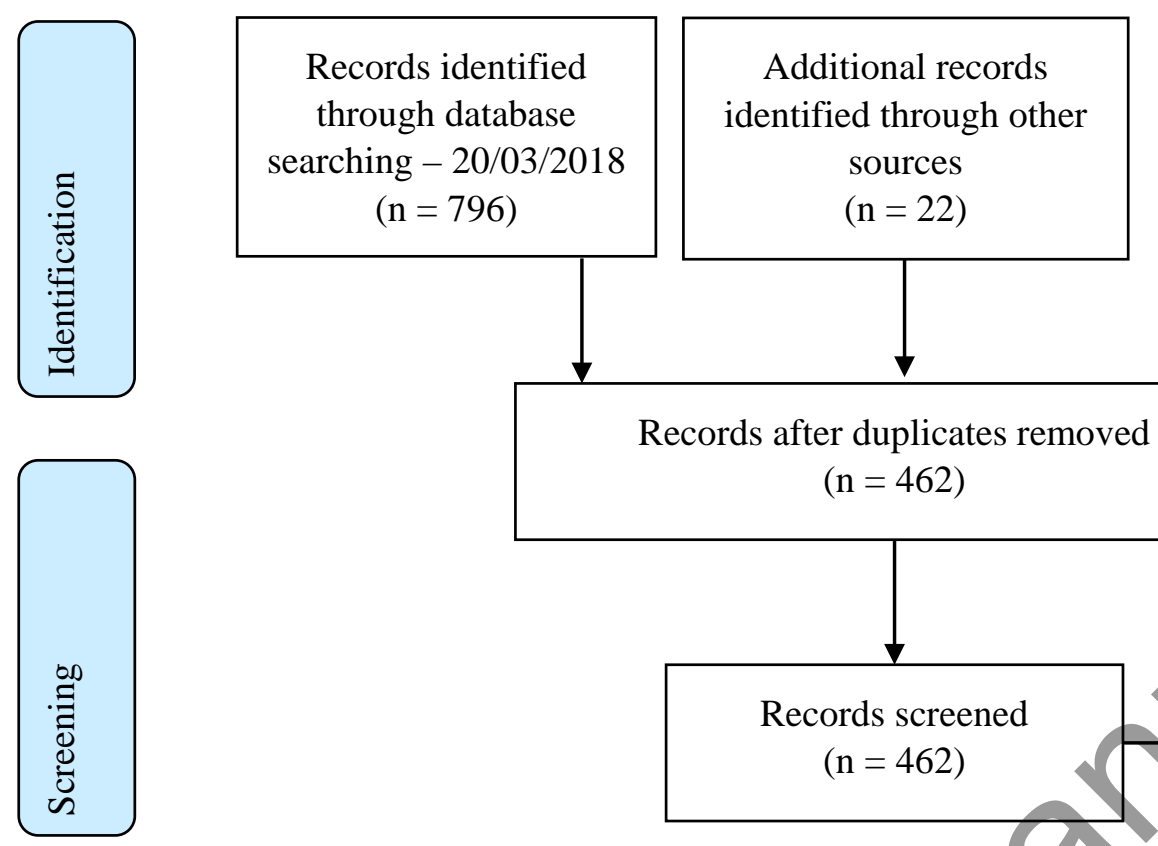
Records identified through database searching - 30/04/2019

$$
(\mathrm{n}=26)
$$

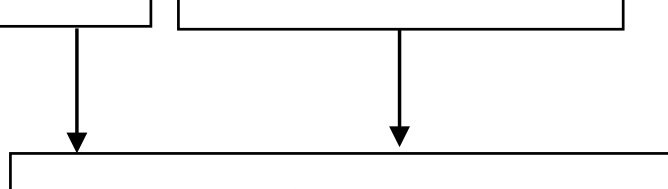

Records after duplicates removed $(n=462)$
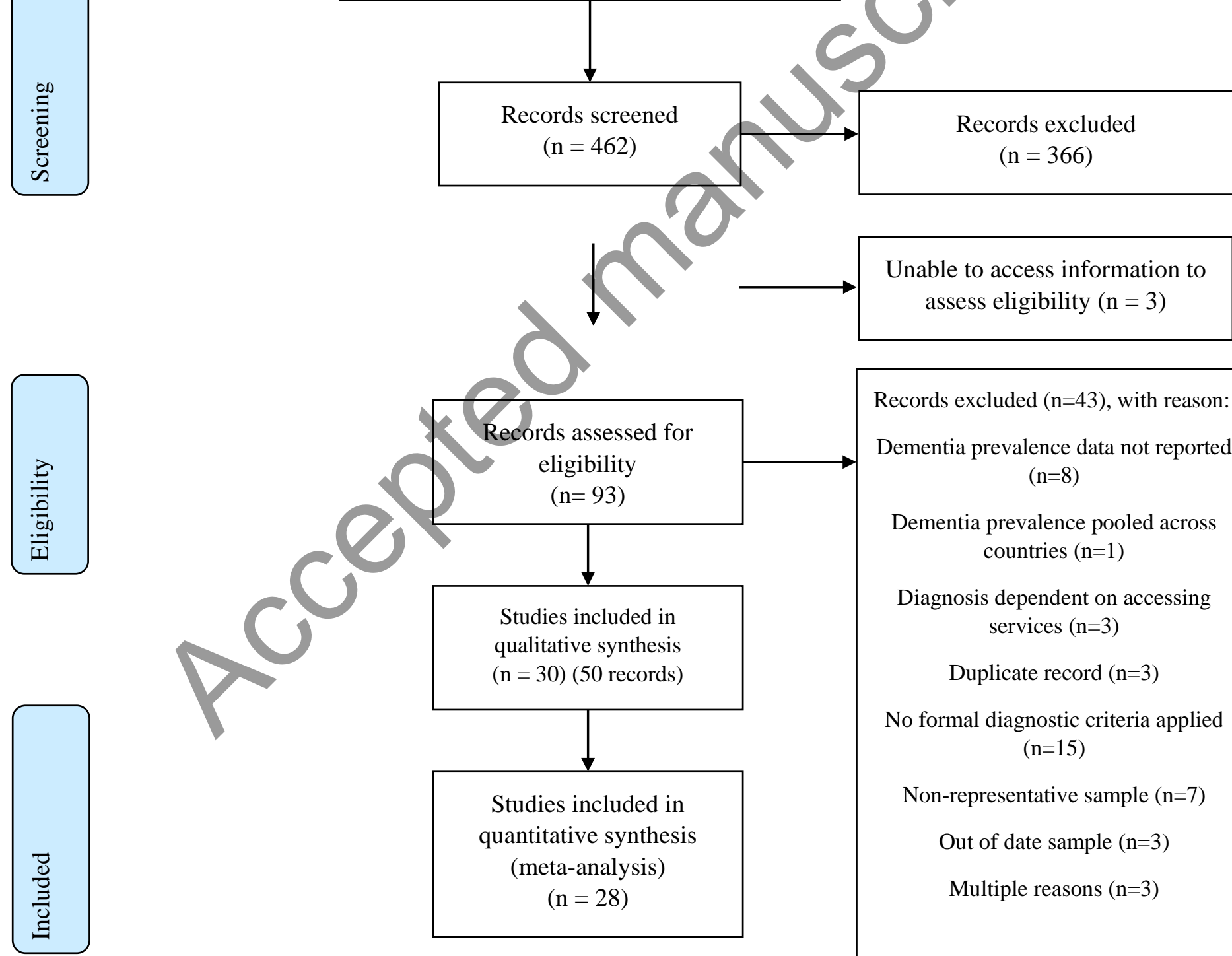

Records excluded ( $n=43)$, with reason:

Dementia prevalence data not reported

$$
(n=8)
$$

Dementia prevalence pooled across countries $(n=1)$

Diagnosis dependent on accessing services $(n=3)$

Duplicate record $(n=3)$

No formal diagnostic criteria applied $(n=15)$

Non-representative sample $(n=7)$

Out of date sample $(n=3)$

Multiple reasons $(n=3)$

Figure 1. Flow chart of systematic review process. 
Figure 2. Dementia prevalence estimates within Brazil, split by diagnostic criteria.

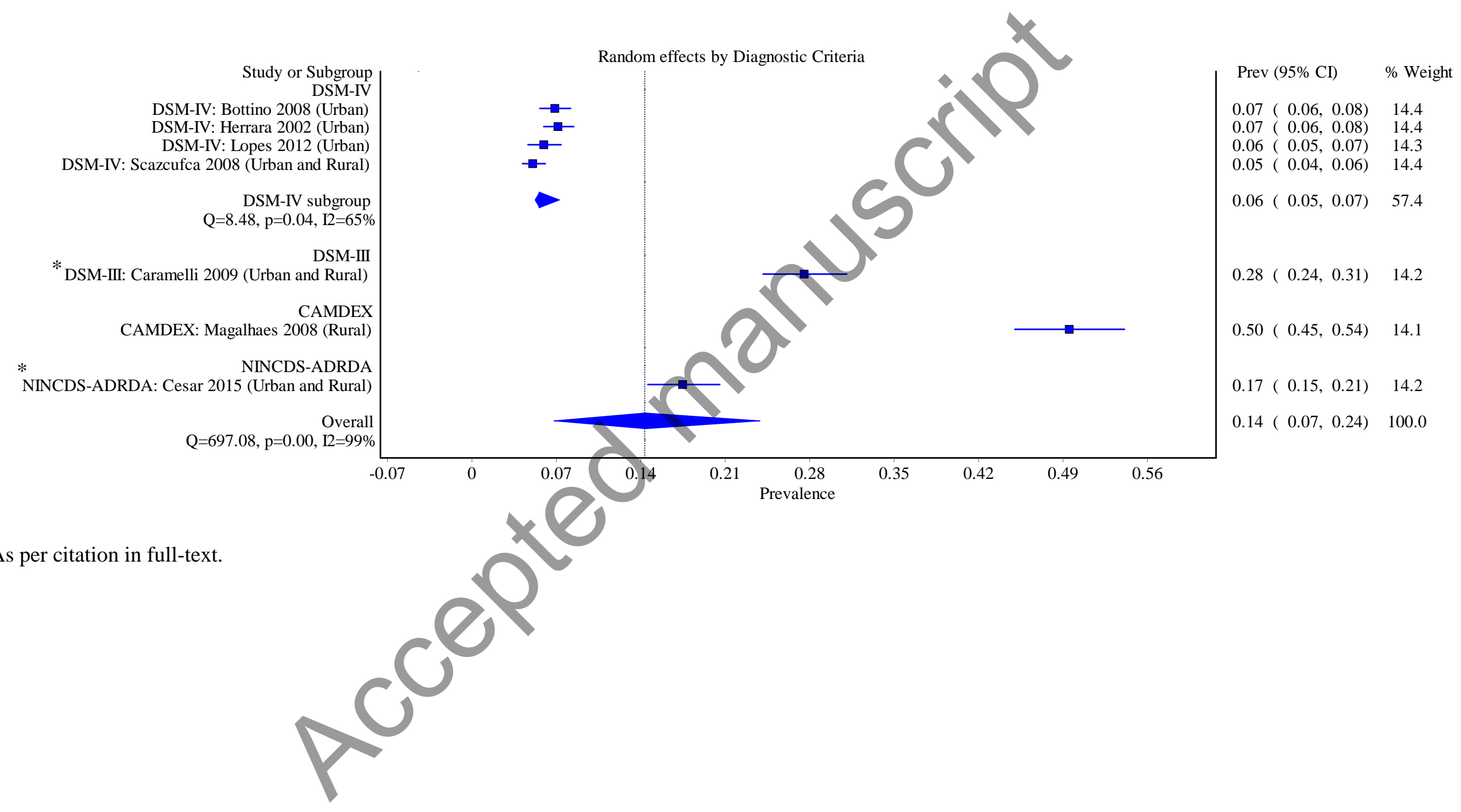


Figure 3. Dementia prevalence estimates within India, split by diagnostic criteria.

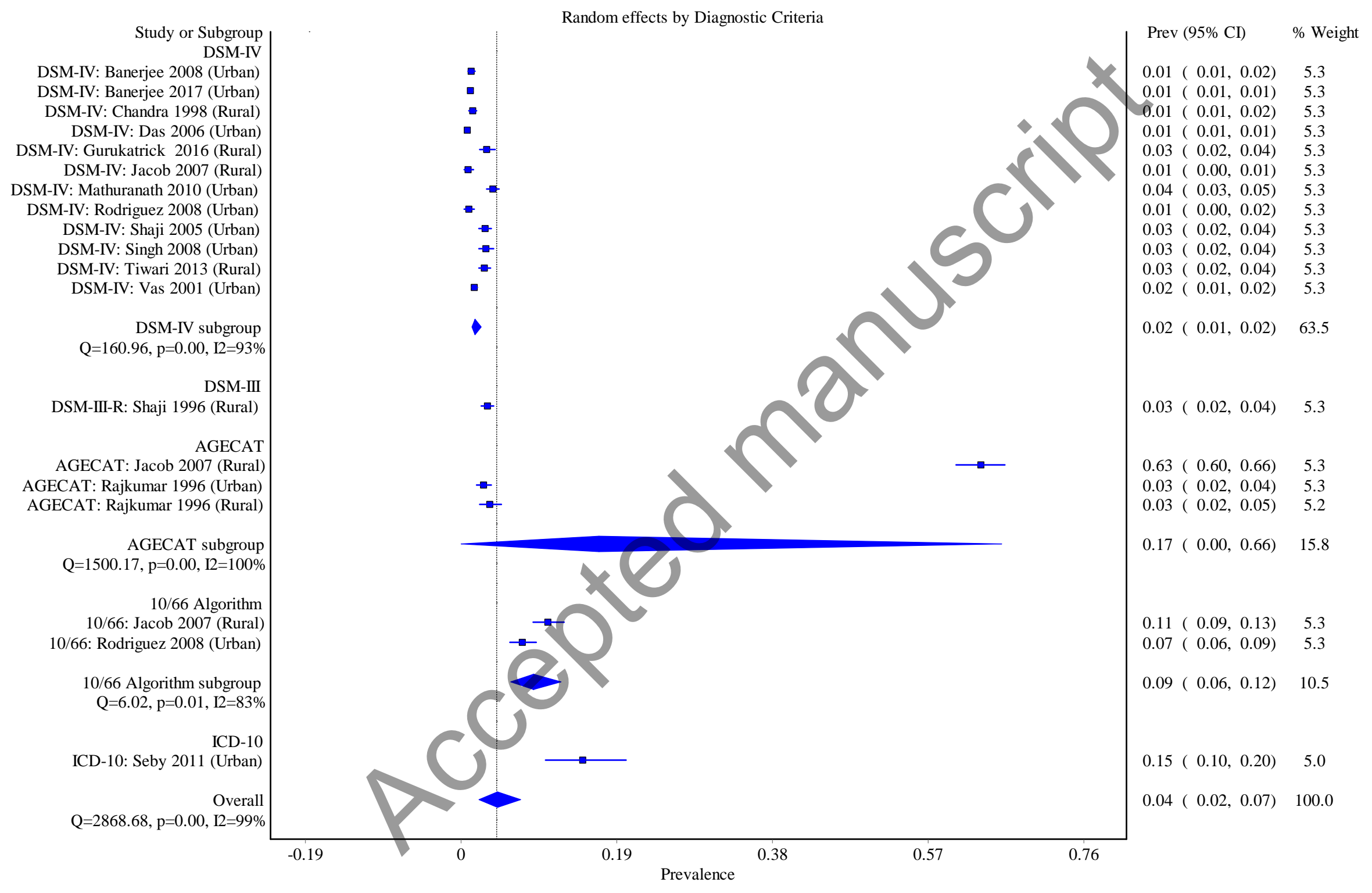


Figure 4. Dementia prevalence estimates within Jamaica.

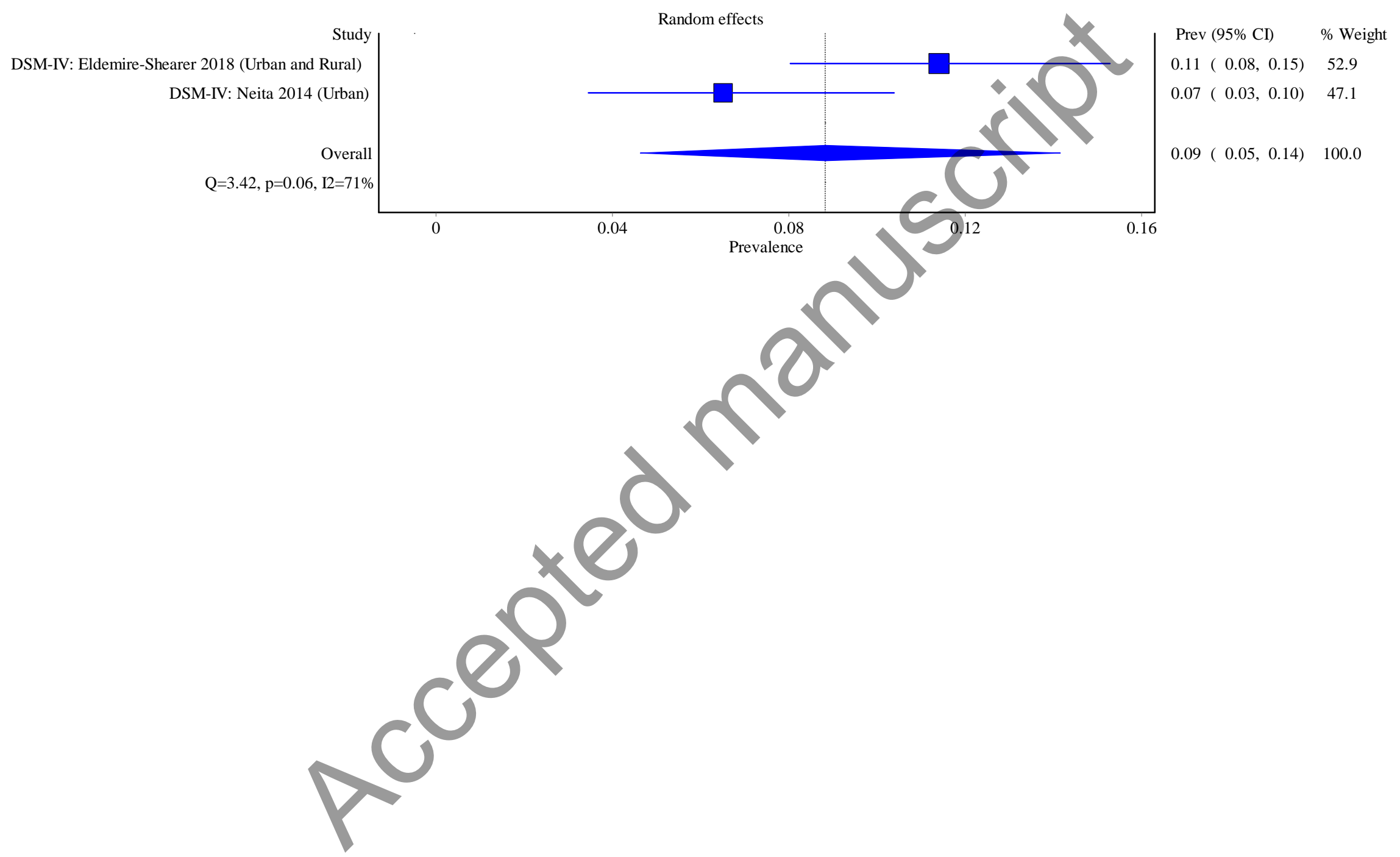


Figure 5. Dementia prevalence estimates within Mexico, split by diagnostic criteria.

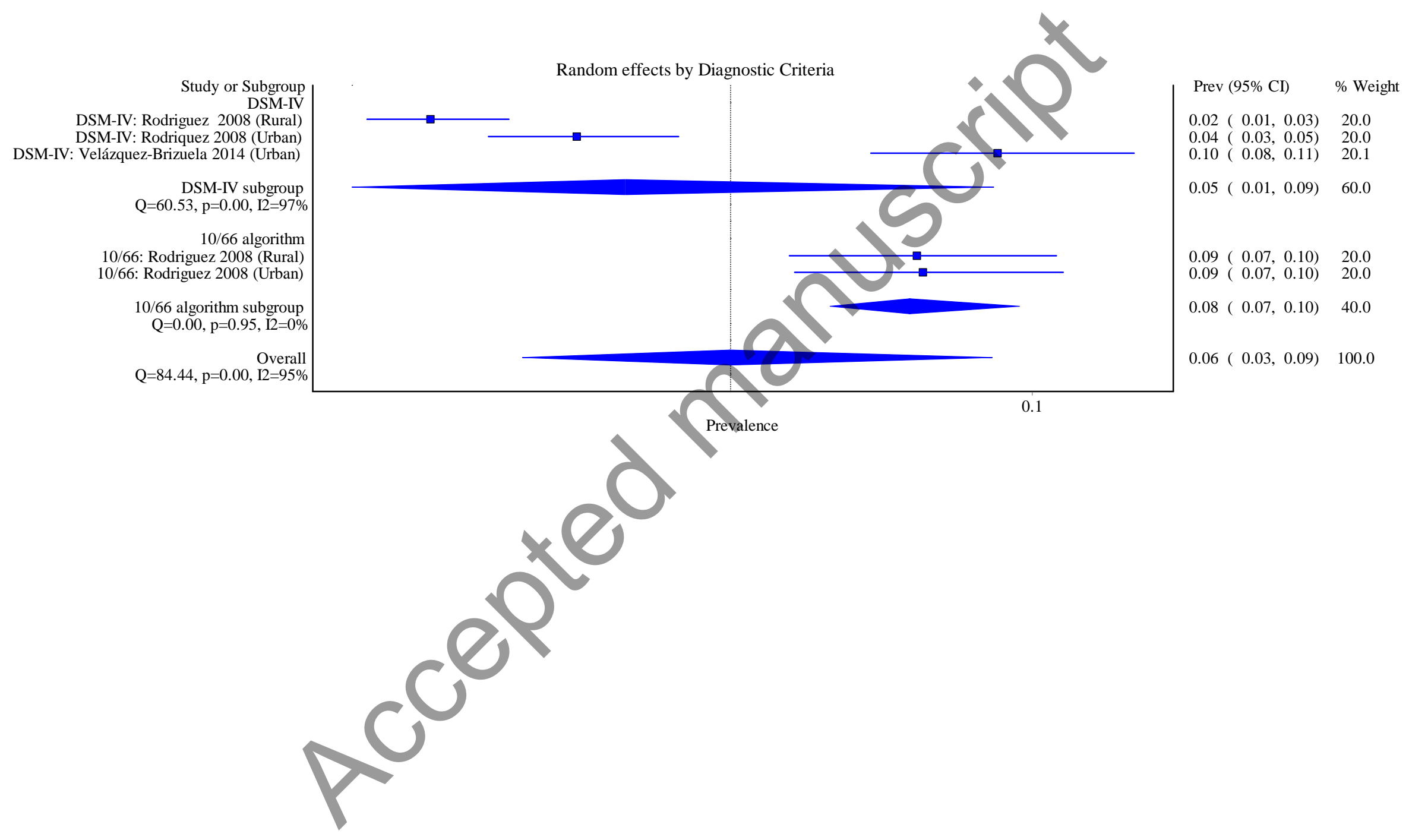




\section{Appendix A}

Search strategy and associated hits

Scopus

- TITLE ( dementia) AND TITLE-ABS ( prevalence OR epidemiolog*) AND TITLE-ABS ( "South Africa" OR indonesia OR india OR jamaica OR mexico OR brazil OR kenya )

- 127 hits, $20 / 03 / 18$

- 4 hits, 30/04/19

PsycINFO

- ((TI( dementia)) AND ( prevalence OR epidemiolog*) AND ( "South Africa" OR indonesia OR india OR jamaica OR mexico OR brazil OR kenya))

- 172 hits, 20/03/18

- 2 hits, 30/04/19

Web of Science

- $\mathrm{TI}=($ dementia $)$ AND TS= (prevalence OR epidemiolog* $)$ AND TS= ("South Africa" OR indonesia OR india OR jamaica OR mexico OR brazil OR kenya)

- 173 hits, $20 / 03 / 18$

- 7 hits, 30/04/2019

Pubmed:

- ((dementia [Title] OR dementia [MeSH Terms]) AND (epidemiolog* [Title/Abstract] OR epidemiology [MeSH Terms] OR prevalence [MeSH Terms] OR prevalence[Title/Abstract])) AND (("South Africa" [Title/Abstract] OR indonesia [Title/Abstract] OR india [Title/Abstract] OR jamaica [Title/Abstract] OR mexico [Title/Abstract] OR brazil [Title/Abstract] OR kenya[Title/Abstract]))

- 219 hits, $20 / 03 / 18$

- 8 hits, 30/04/2019 
SciELO:

- ( (prevalence OR epidemiolog*) AND (mexico OR brazil OR jamaica)) AND (ti:(dementia))

- 23 hits, 20/03/18

- 2 hits, 30/5/18

Opengrey.eu

- Dementia AND prevalence

- 27 hits, 20/03/2018

- 0 hits, 30/05/2019

Google Scholar:

- allintitle: dementia prevalence "South Africa" OR indonesia OR india OR jamaica OR mexico OR brazil OR Kenya

- 55 hits, 20/03/18

- 3 hits, 30/04/2019 


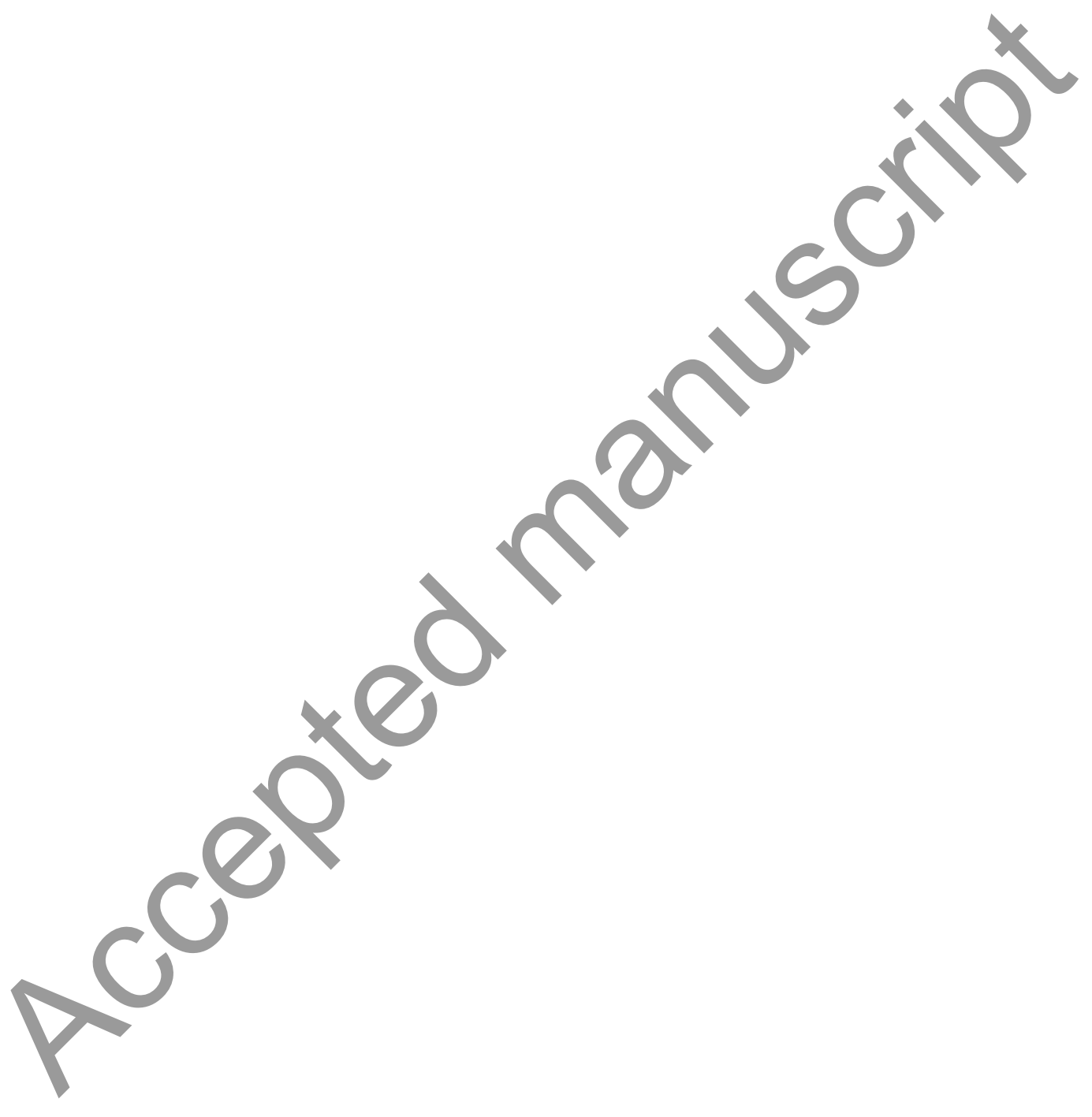


Appendix B

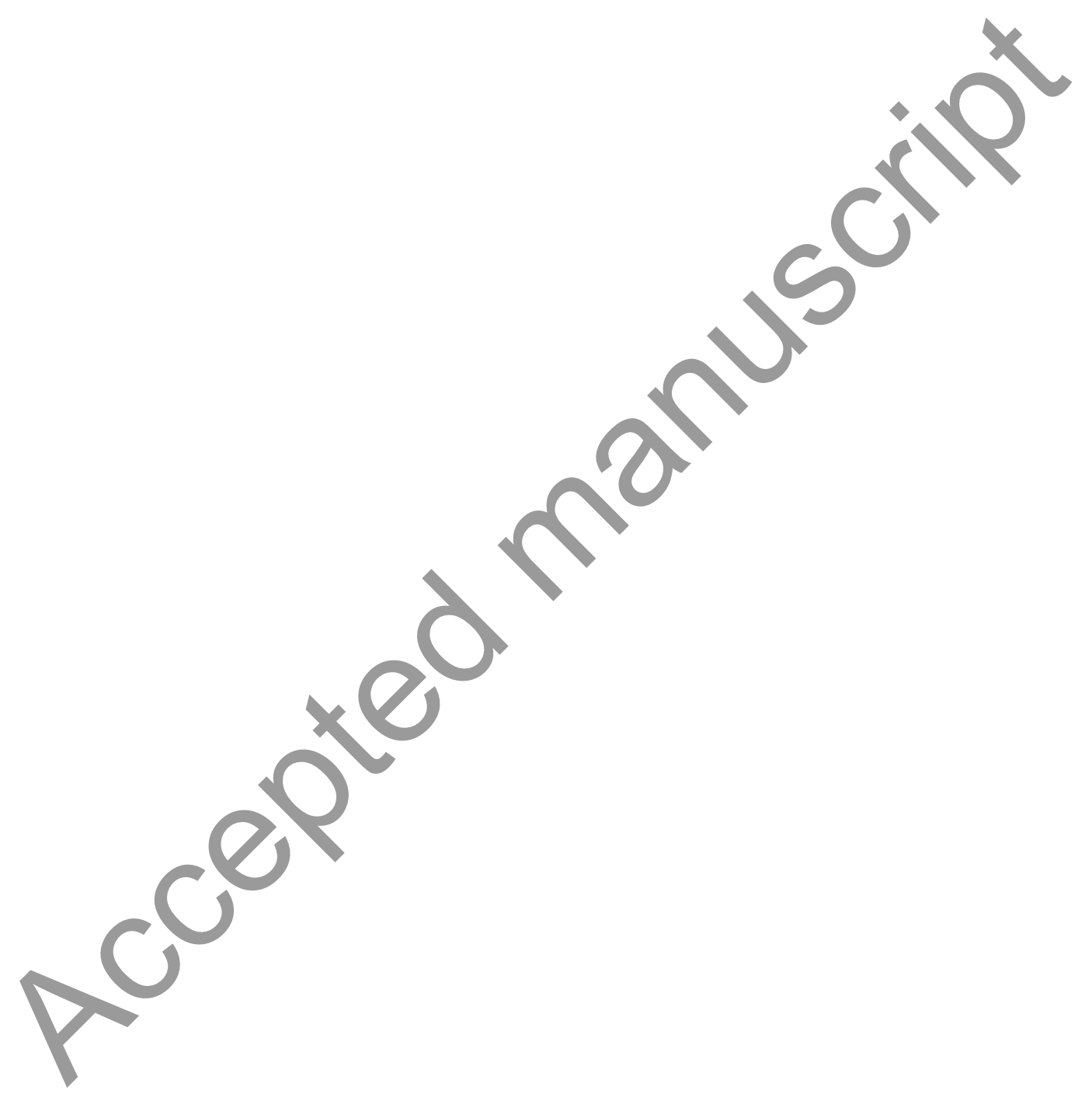


Description of included studies

\begin{tabular}{|c|c|c|c|c|c|c|c|c|c|c|}
\hline 总 & Record ID & 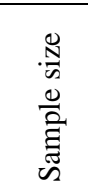 & $\begin{array}{l}\text { Key } \\
\text { Inclusion } \\
\text { Criteria }\end{array}$ & 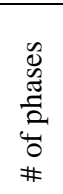 & Setting & Sampling Frame & Participant Identification & Study measures & 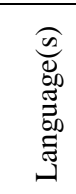 & 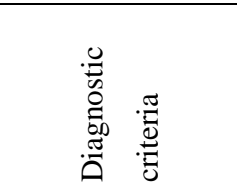 \\
\hline \multicolumn{11}{|c|}{ Brazil } \\
\hline 咅 & $\begin{array}{l}13480301 \\
13480300 \\
15752111\end{array}$ & 1563 & Aged $\geq 60$ & 2 & Urban & $\begin{array}{l}\text { "A cluster random sampling of a } \\
\text { population of individuals aged } \\
60 \text { years and over from three } \\
\text { different socioeconomic classes } \\
\text { (upper, middle and low) was used } \\
\text { in Sao Paulo" }\end{array}$ & $\begin{array}{l}\text { “...blocks of } 10 \text { domiciles } \\
\text { were randomly chosen in each } \\
\text { of the } 90 \text { selected census } \\
\text { sectors.” }\end{array}$ & $\begin{array}{ll}\text { - } & \text { MMSE } \\
\text { - } & \text { FOME } \\
\text { - } & \text { IQCODE } \\
\text { - } & \text { BADL } \\
\text { - } & \text { CAMDEX } \\
\text { - } & \text { CAMCOG }\end{array}$ & NR & DSM-IV \\
\hline 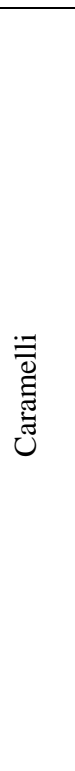 & 15752121 & 639 & Aged $\geq 75$ & 3 & $\begin{array}{l}\text { Both } \\
\text { (Caramelli, } \\
\text { 2009) }\end{array}$ & $\begin{array}{l}\text { "Since a complete and updated list } \\
\text { of these elderly individuals was not } \\
\text { readily available, an active search } \\
\text { was undertaken. We contacted } \\
\text { family health program agents from } \\
\text { the municipal government and the } \\
\text { municipality health department."; } \\
\text { "As for institutionalized elderly, the } \\
\text { two existing institutions in town } \\
\text { were visited by the research team." }\end{array}$ & NR & 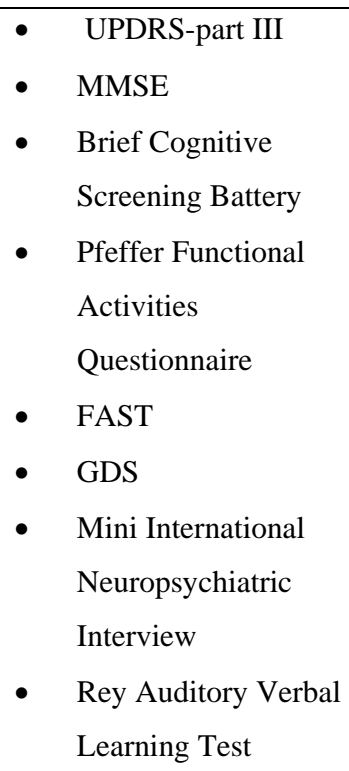 & NR & $\begin{array}{l}\text { DSM-III (as cited } \\
\text { within text) }\end{array}$ \\
\hline
\end{tabular}




\begin{tabular}{|c|c|c|c|c|c|c|c|c|c|c|}
\hline & & & & & & & 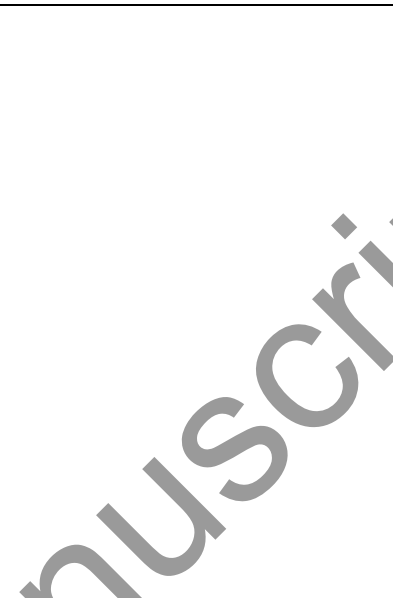 & 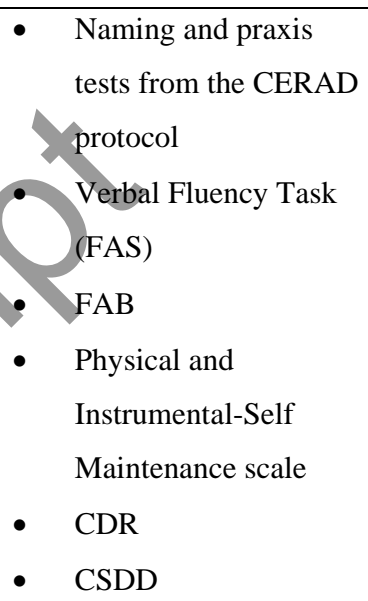 & & \\
\hline 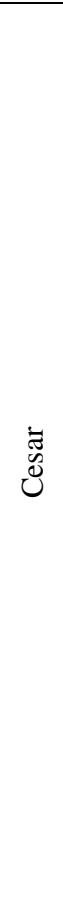 & $\begin{array}{l}13480321 \\
\text { N001 } \\
13280322 \\
\text { N003 }\end{array}$ & 630 & Aged $\geq 60$ & 1 & Both & $\begin{array}{l}\text { "According to IBGE there are } 89 \\
\text { sectors (73 urban and } 16 \text { rural) in } \\
\text { Tremembe'. Each census sector } \\
\text { defined by IBGE is a territorial unit } \\
\text { with identified physical limits in } \\
\text { continuous areas, accounting for } \\
\text { uniform households' numbers } \\
\text { (usually } 400 \text { to } 450 \text { dwellers in each } \\
\text { one). Twenty percent of the } \\
\text { households with individuals aged } \\
60 \text { years or more were randomly } \\
\text { selected from each of the } \\
\text { municipality’s census sectors, to } \\
\text { obtain a homogenous representation } \\
\text { of all regions and districts } \\
\text { representing all socioeconomic and } \\
\text { cultural levels.” }\end{array}$ & $\begin{array}{l}\text { "Twenty percent of the } \\
\text { households with individuals } \\
\text { aged } 60 \text { years or more were } \\
\text { then randomly selected, from } \\
\text { both urban and rural areas..." }\end{array}$ & $\begin{array}{ll}\text { - } & \text { MMSE } \\
\text { - } & \text { Brief Cognitive } \\
& \text { Screening Battery } \\
\text { - } & \text { IQCODE } \\
\text { - } & \text { Pfeffer Functional } \\
& \text { Activities } \\
& \text { Questionnaire } \\
\text { - } & \text { ACE-R } \\
\text { - } & \text { MoCA } \\
\text { - } & \text { QMC22 } \\
\text { - } & \text { Verbal fluency test and } \\
& \text { clock drawing. } \\
\text { - } & \text { CSDD } \\
\text { - } & \text { PRIME-MD } \\
\end{array}$ & NR & $\begin{array}{l}\text { "Dementia was } \\
\text { diagnosed based } \\
\text { on clinical criteria } \\
\text { updated by the } \\
\text { National Institute } \\
\text { on Aging } \\
\text { according to } \\
\text { criteria of } \\
\text { McKhann et al for } \\
\text { the diagnosis of } \\
\text { all-cause } \\
\text { dementia and } \\
\text { recommended by } \\
\text { the Brazilian } \\
\text { Academy of } \\
\text { Neurology.” }\end{array}$ \\
\hline
\end{tabular}




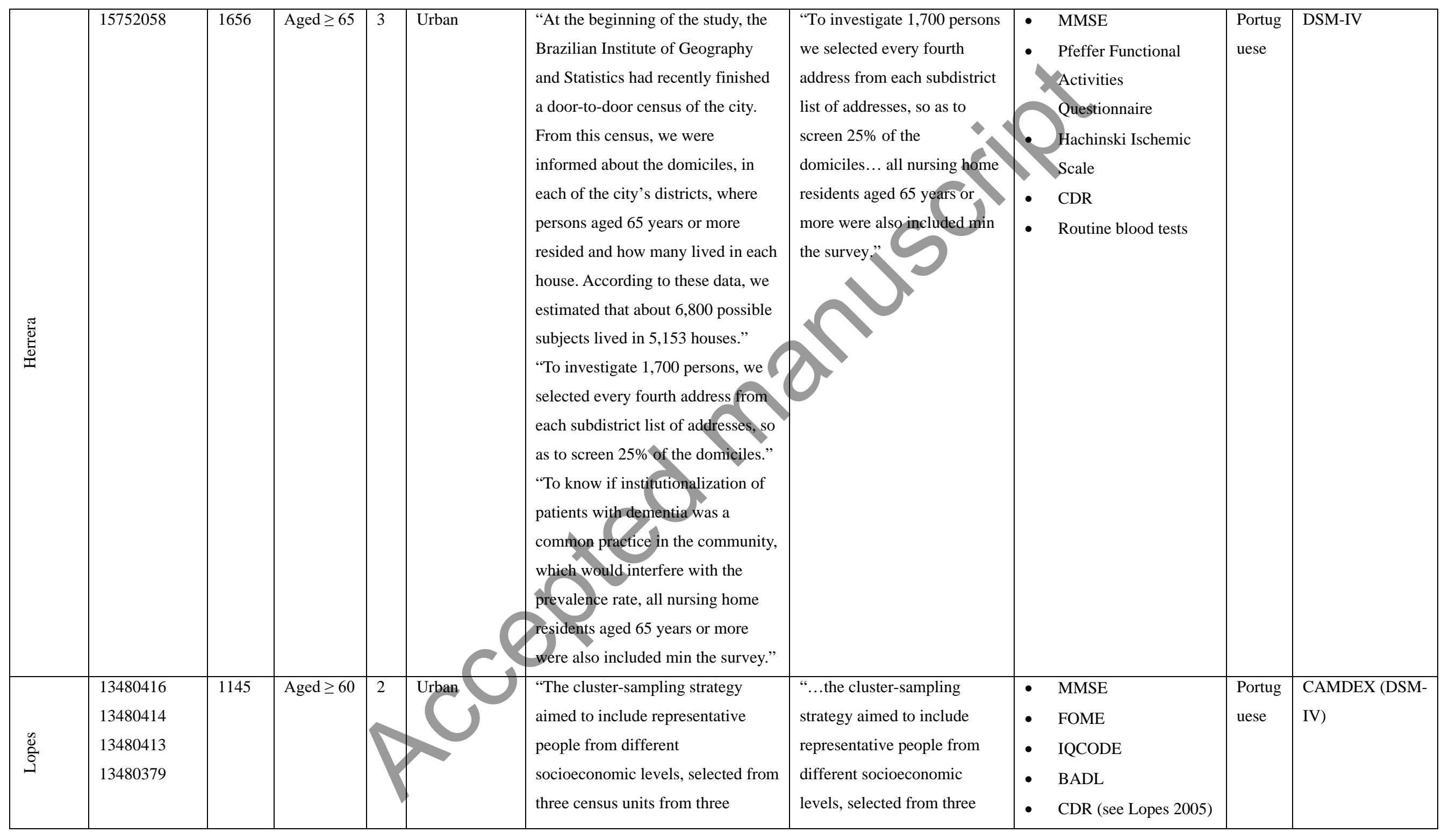




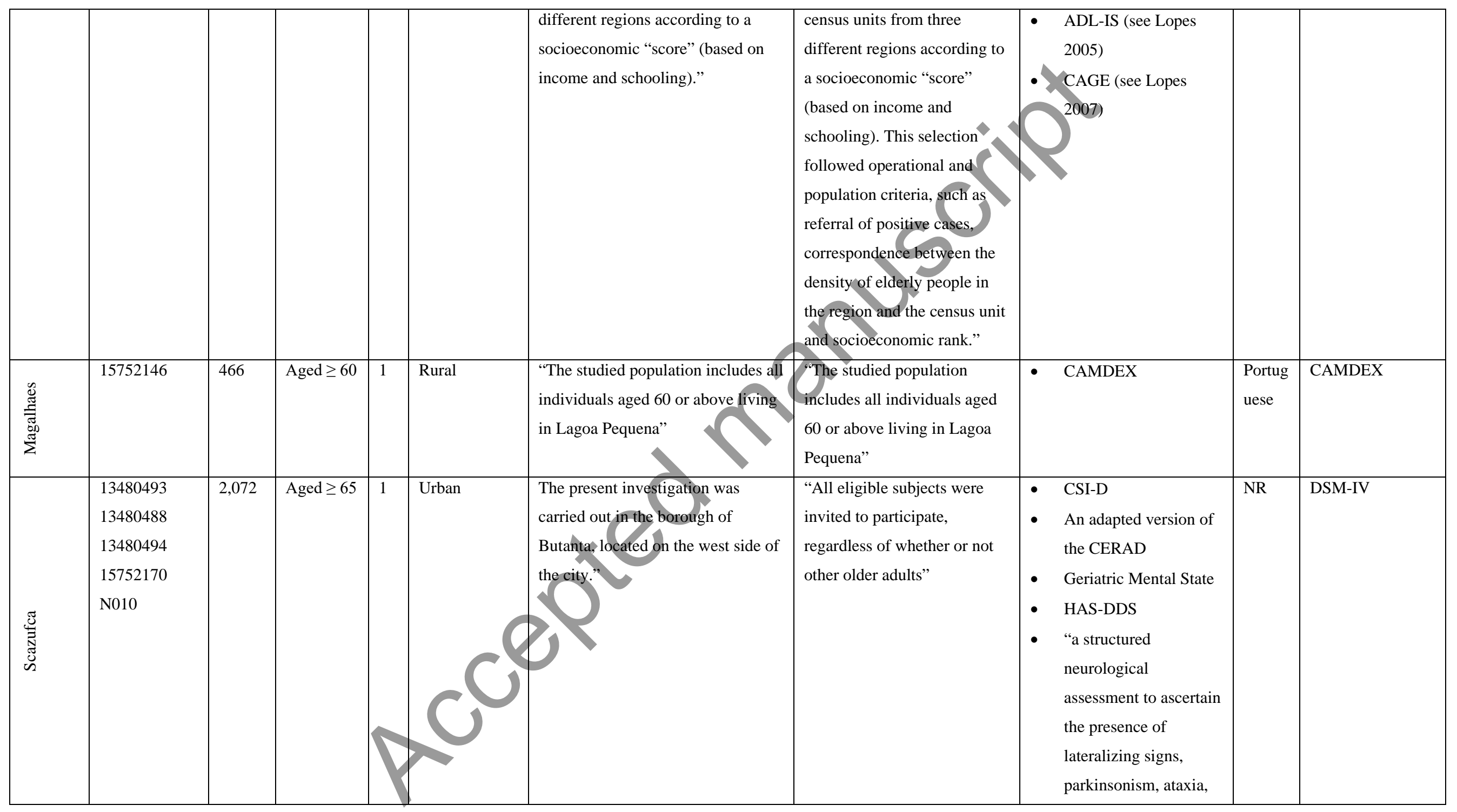




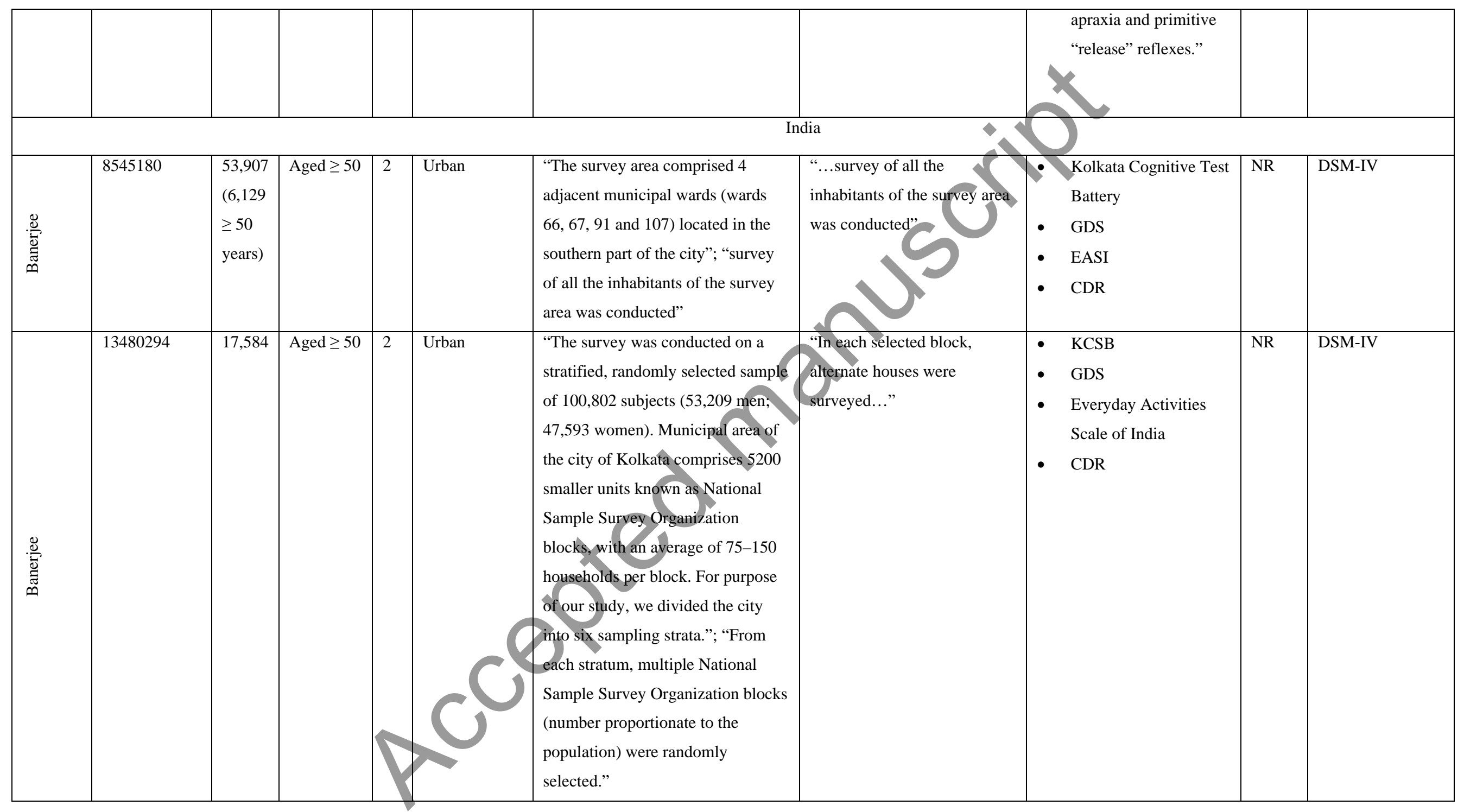




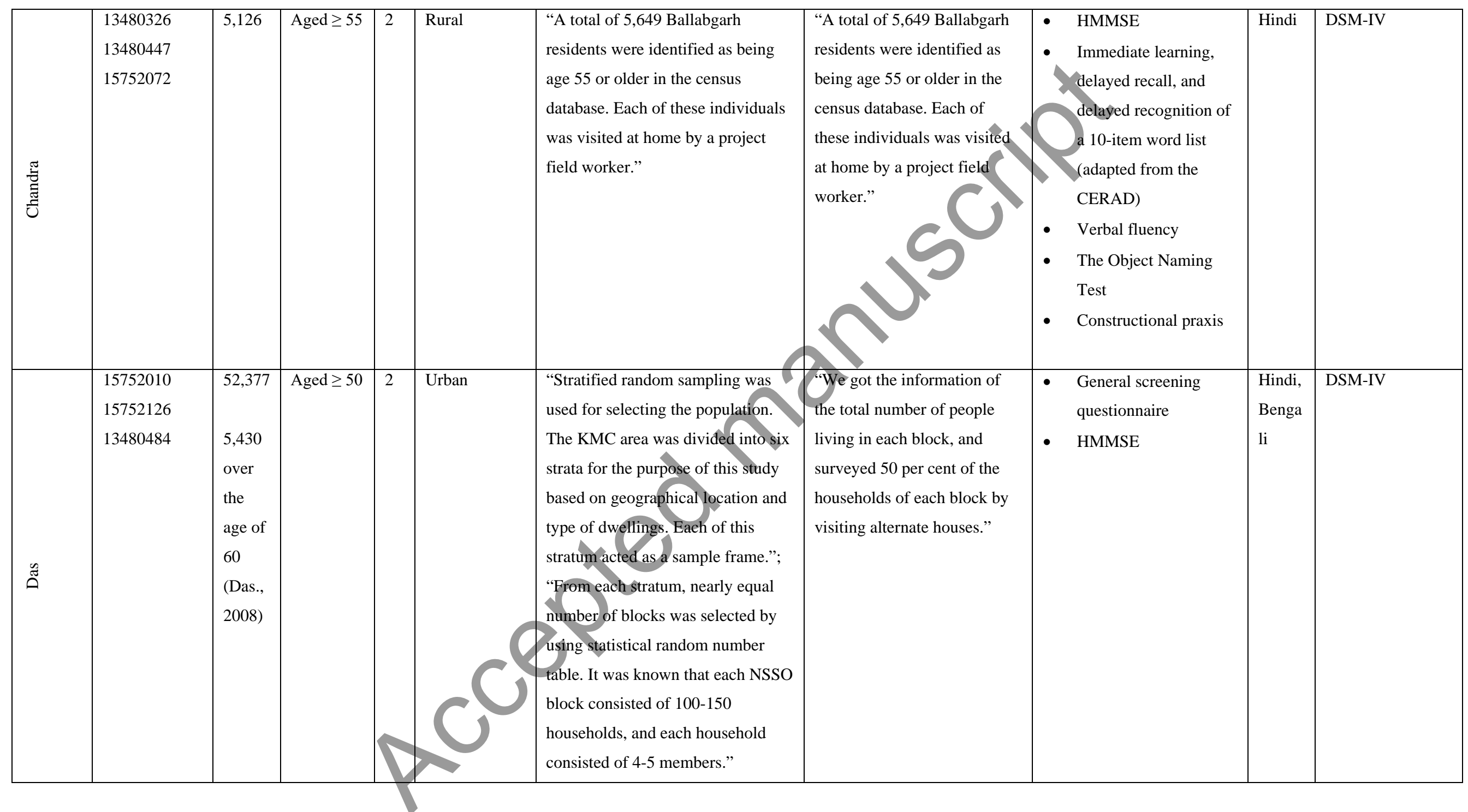




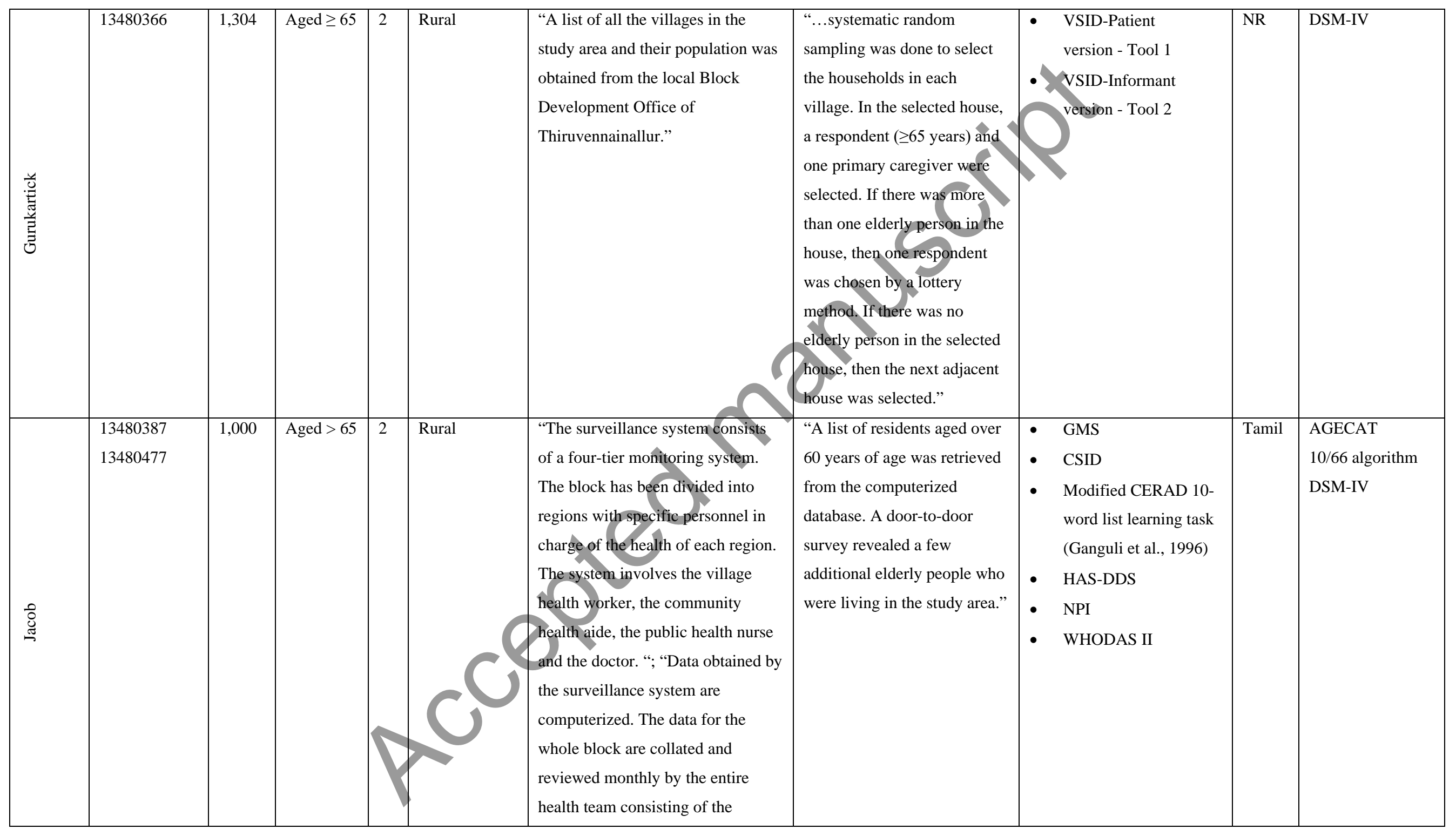




\begin{tabular}{|c|c|c|c|c|c|c|c|c|c|c|}
\hline & & & & & & $\begin{array}{l}\text { community health workers, health } \\
\text { aides, community health nurses, } \\
\text { doctors and other development } \\
\text { staff.” }\end{array}$ & & & & \\
\hline 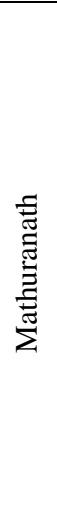 & $\begin{array}{l}13480423 \\
15752110\end{array}$ & 2,466 & Aged $\geq 55$ & 2 & Urban & $\begin{array}{l}\text { "Sampling frame consisted of } \\
41920 \text { subjects from four of the } \\
\text { eight wards (administrative districts } \\
\text { of the city corporation) of } \\
\text { Trivandrum. } \\
\text { Residents of these four wards } \\
\text { provided a good admixture and } \\
\text { faithful representation of the socio- } \\
\text { economically and culturally diverse } \\
\text { population of Trivandrum." }\end{array}$ & $\begin{array}{l}\text { "The census information and } \\
\text { the Election Commission's } \\
\text { database identified } 2932 \\
\text { individuals to be } 55 \text { years of } \\
\text { age." All approached in a } \\
\text { "door knocking survey" }\end{array}$ & $\begin{array}{l}\text { ACE } \\
\text { An IADL-E was } \\
\text { specifically developed } \\
\text { for the local elders } \\
\text { (Mathuranath et al., } \\
\text { 2005). }\end{array}$ & $\begin{array}{l}\text { Malay } \\
\text { alam }\end{array}$ & DSM-IV \\
\hline
\end{tabular}




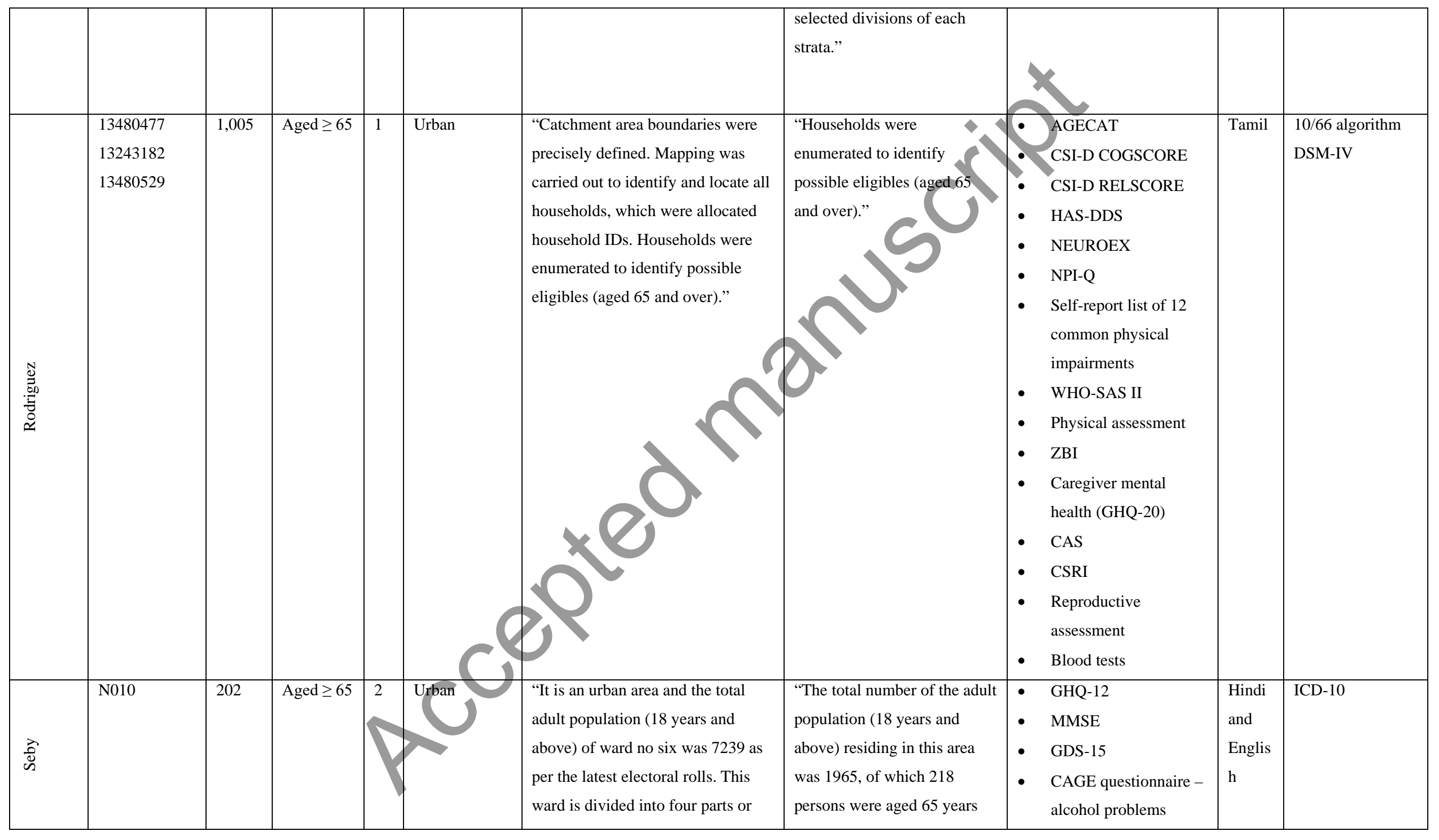




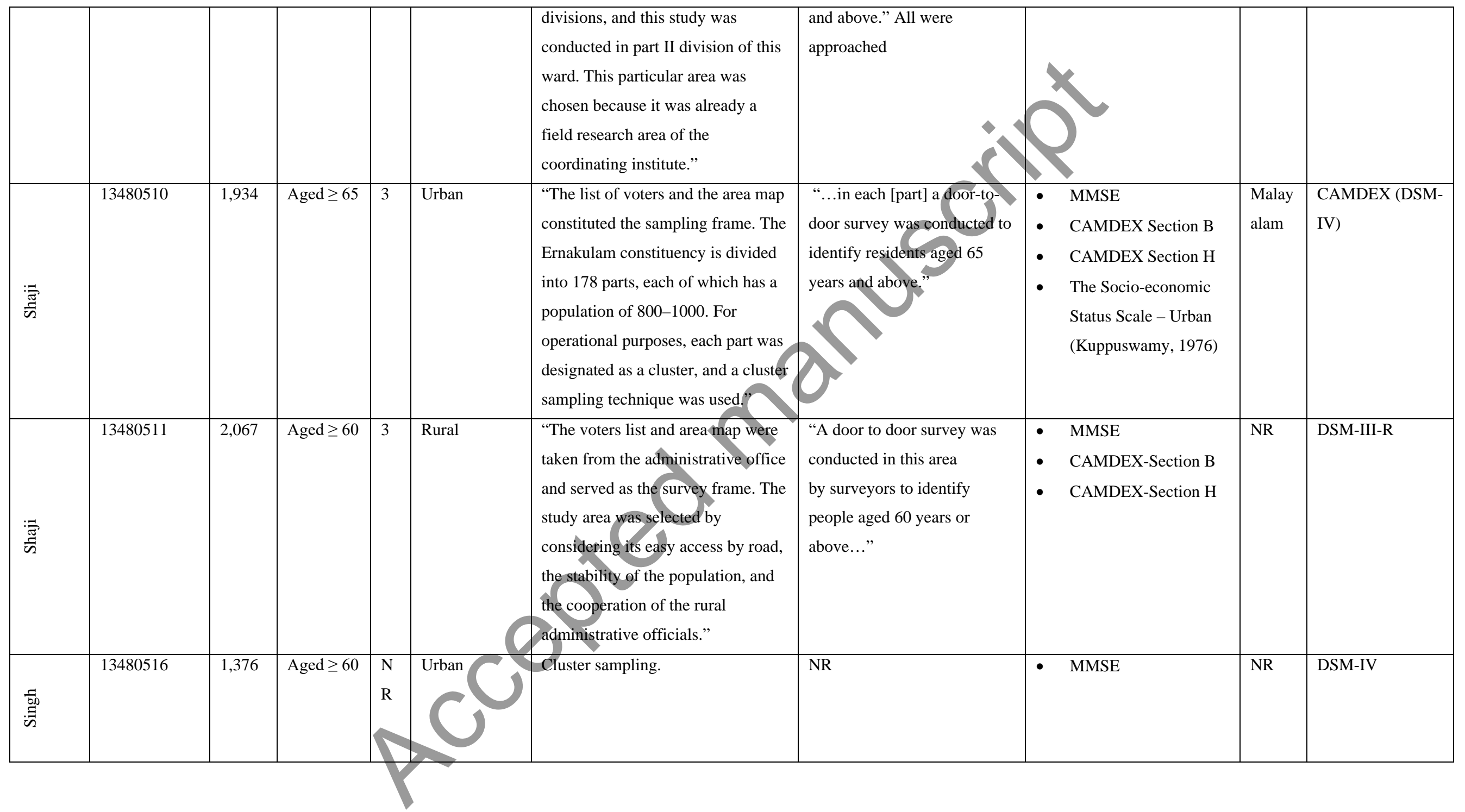




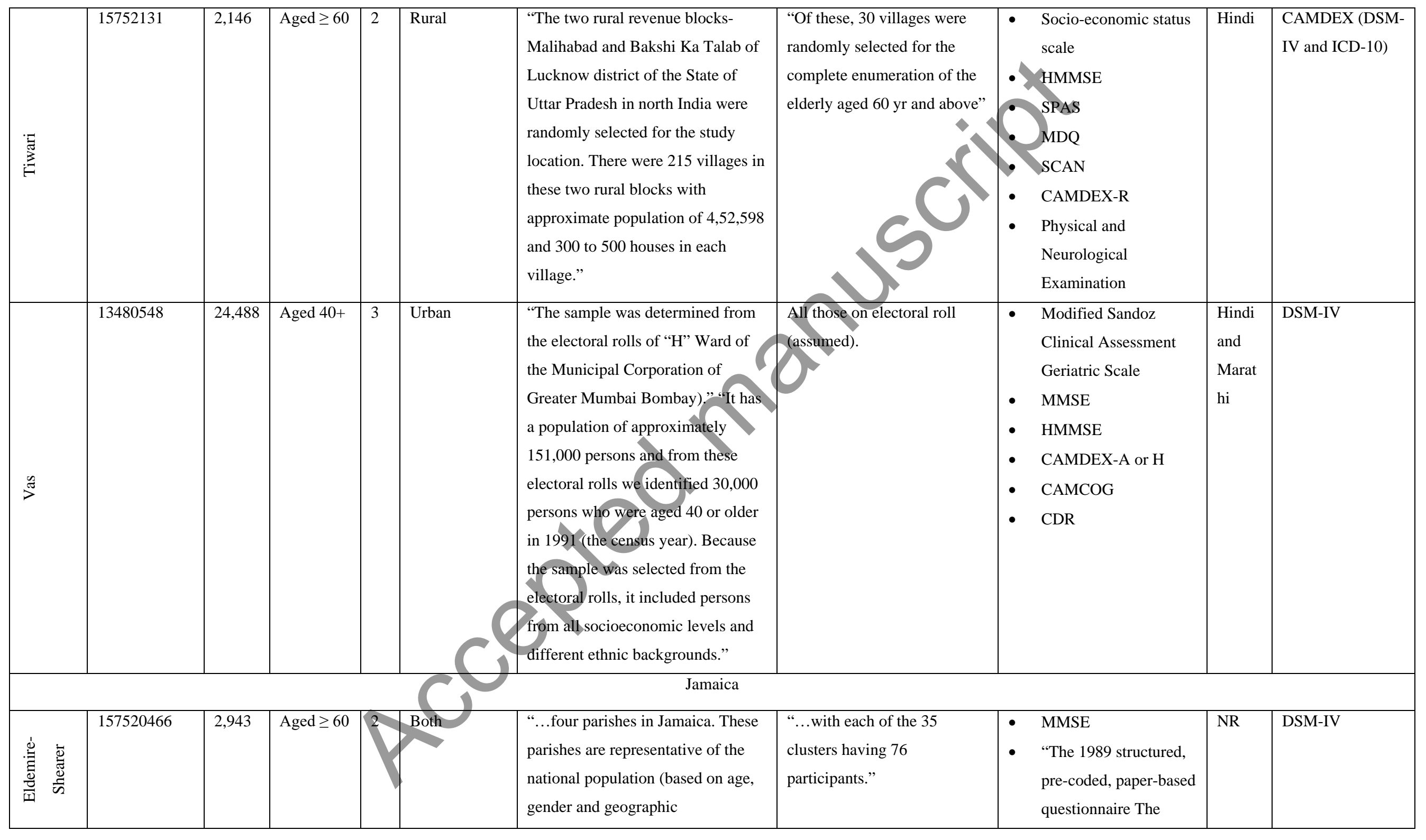




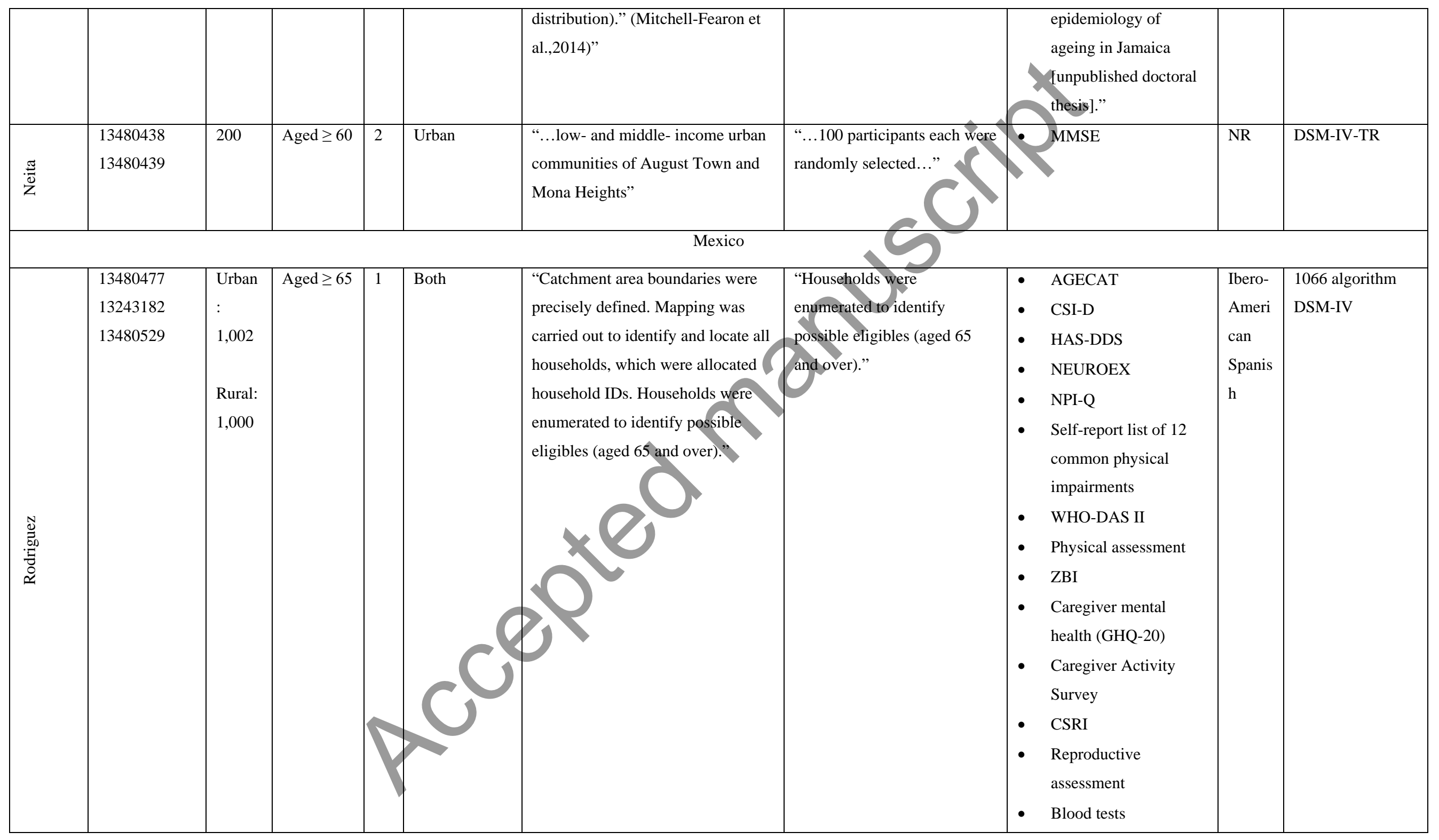




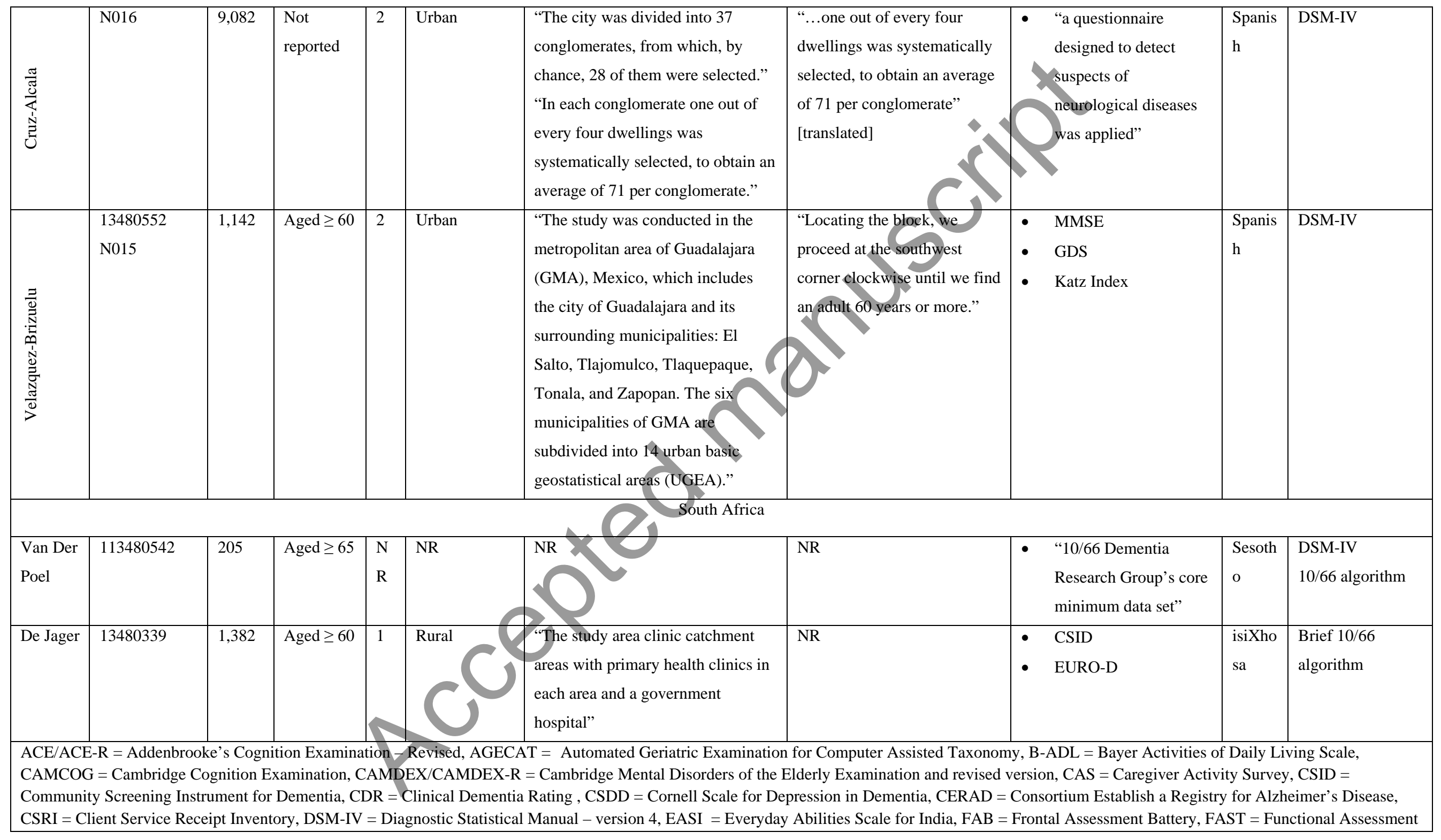




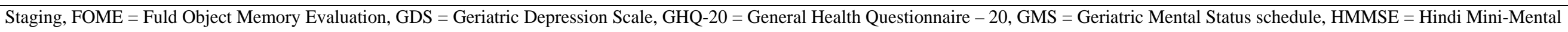
State Examination, HAS-DDS = History and Aetiology Schedule - Dementia Diagnosis and Subtype, IADL-E = Instrumental Activities of Daily Living Scale for the Elderly, IQCODE = Informant

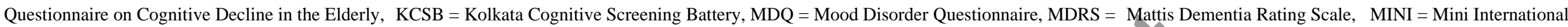

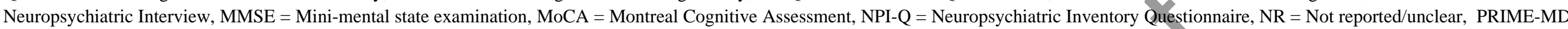

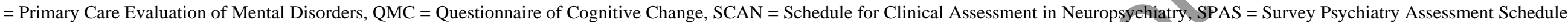

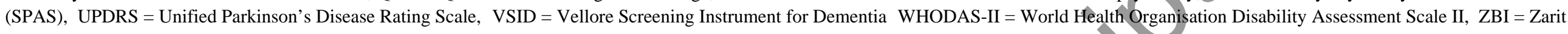
Burden Inventory,

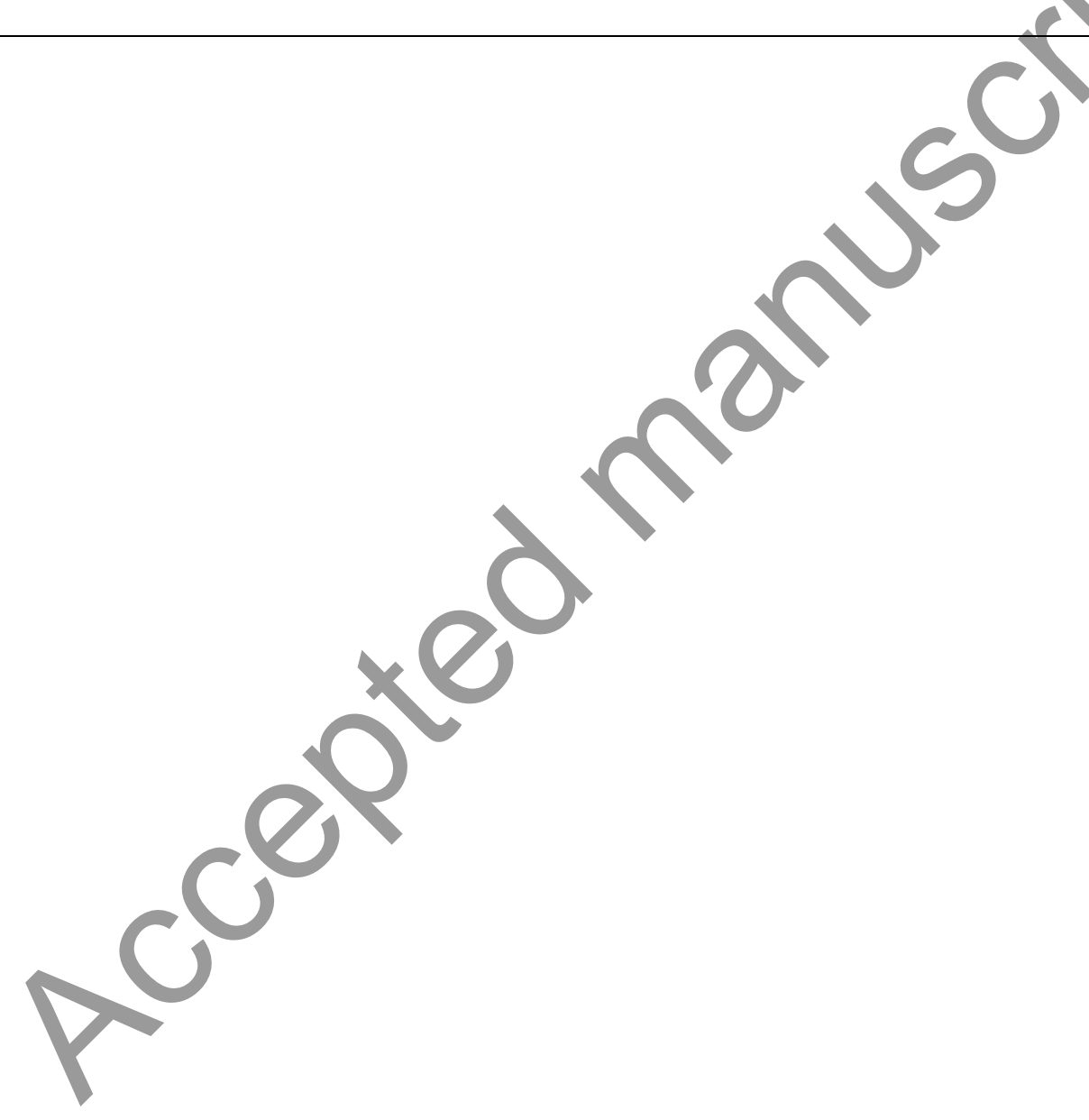




\section{Appendix C}

List of excluded studies, alongside rationale.

\begin{tabular}{|c|c|c|c|c|}
\hline $\begin{array}{c}\text { First } \\
\text { author, } \\
\text { Year }\end{array}$ & $\begin{array}{l}\text { Record } \\
\text { ID }\end{array}$ & Country & Reason & Evidence \\
\hline \multicolumn{5}{|c|}{ Non-Specific } \\
\hline $\begin{array}{c}\text { Andreasen } \\
2014\end{array}$ & 13480291 & - & $\begin{array}{l}\text { Dementia prevalence } \\
\text { pooled across } \\
\text { countries }\end{array}$ & - \\
\hline $\begin{array}{c}\text { Prince } \\
2009\end{array}$ & 8545171 & - & Narrative article & \\
\hline $\begin{array}{c}\text { Rodriguez } \\
2008\end{array}$ & 13480478 & - & Duplicate & $\begin{array}{l}\text { Identified as a duplicate upon } \\
\text { accessing the full-text (13480477) }\end{array}$ \\
\hline Shaji 2010 & 15752154 & - & Review article & \\
\hline \multicolumn{5}{|l|}{ Brazil } \\
\hline $\begin{array}{c}\text { Barbosa } \\
2009\end{array}$ & N002 & Brazil & $\begin{array}{l}\text { Non-representative } \\
\text { sample }\end{array}$ & $\begin{array}{l}\text { "were having been a client of the } \\
\text { health care plan for at least } 12 \\
\text { months" }\end{array}$ \\
\hline $\begin{array}{c}\text { Bendetti } \\
2008\end{array}$ & N022 & & $\begin{array}{l}\text { No formal diagnostic } \\
\text { criteria (with face } \\
\text { validity) applied. }\end{array}$ & $\begin{array}{l}\text { "To analyze dementia, the } \\
\text { classification used was } \\
\text { "does not present dementia" ( }<2 \\
\text { points) and "presents } \\
\text { dementia" ( } \geq 3 \text { points)." }\end{array}$ \\
\hline Burla 2013 & 15752113 & Brazil & Review article & - \\
\hline Burla 2013 & 15752008 & Brazil & Duplicate & $\begin{array}{l}\text { Identified as duplicate upon } \\
\text { accessing full-text (15752113) }\end{array}$ \\
\hline $\begin{array}{l}\text { Caixeta } \\
2004\end{array}$ & 13480313 & Brazil & $\begin{array}{l}\text { Diagnosis dependent } \\
\text { on accessing service }\end{array}$ & $\begin{array}{l}\text { "We evaluated } 70 \text { demented } \\
\text { patients, consecutively attended in } \\
\text { three different care settings: a public } \\
\text { psychiatric outpatient clinic, a } \\
\text { private memory clinic and the } \\
\text { university outpatient dementia } \\
\text { ambulatory" }\end{array}$ \\
\hline
\end{tabular}




\begin{tabular}{|c|c|c|c|c|}
\hline $\begin{array}{c}\text { Caldas } \\
2012\end{array}$ & 15752175 & Brazil & $\begin{array}{l}\text { No formal diagnostic } \\
\text { criteria (with face } \\
\text { validity) applied. }\end{array}$ & $\begin{array}{l}\text { "Mean total score on the LCT was } \\
26.3 \pm 4.1 \text {; this value is above the } \\
\text { cut-off proposed for the screening } \\
\text { of dementia for this instrument ( } 22 \\
\text { points). Mean total score on the } \\
\text { MMSE was } 23.4 \pm 3.6 \text {, oscillating } \\
\text { between the case/no case } \\
\text { classification proposed by Almeida, } \\
\text { in 1998" }\end{array}$ \\
\hline Laks 2005 & N021 & Brazil & $\begin{array}{l}\text { No dementia } \\
\text { prevalence data } \\
\text { reported }\end{array}$ & $\begin{array}{l}\text { Only the MMSE and the Pfeffer } \\
\text { Functional Activities Questionnaire } \\
\text { scores reported. }\end{array}$ \\
\hline $\begin{array}{l}\text { Lopes } \\
2007\end{array}$ & N004 & Brazil & $\begin{array}{l}\text { No dementia } \\
\text { prevalence data } \\
\text { reported }\end{array}$ & $\begin{array}{l}\text { "The instruments for detecting } \\
\text { cognitive and functional impairment } \\
\text { (CFI)" }\end{array}$ \\
\hline $\begin{array}{l}\text { Lourenco } \\
2014\end{array}$ & 15752013 & Brazil & accessing & $\begin{array}{l}\text { "847 elderly individuals derived } \\
\text { from a sample stratified by gender } \\
\text { and age, who were clients of a } \\
\text { Brazilian private health plan" }\end{array}$ \\
\hline $\begin{array}{c}\text { Meguro } \\
2001\end{array}$ & 13480428 & Brazil & $\begin{array}{l}\text { Non-representative } \\
\text { sample }\end{array}$ & $\begin{array}{l}\text { “...elderly Japanese immigrants } \\
\text { living in Brazil were examined” }\end{array}$ \\
\hline $\begin{array}{l}\text { Ramos- } \\
\text { Cerqueira } \\
2005\end{array}$ & & & $\begin{array}{l}\text { Non-representative } \\
\text { sample }\end{array}$ & $\begin{array}{l}\text { "All individuals aged } 65 \text { and older, } \\
\text { residents in the urban area of Piraju, } \\
\text { a town in Sao Paulo State, Brazil, } \\
\text { routinely seen by CHWs } \\
\text { [Community Health Workers], were } \\
\text { included in the present study." }\end{array}$ \\
\hline $\begin{array}{c}\text { Ribeiro } \\
2011\end{array}$ & N007 & Brazil & $\begin{array}{l}\text { Non-representative } \\
\text { sample }\end{array}$ & $\begin{array}{l}\text { "were having been a client of the } \\
\text { health care plan for at least } 12 \\
\text { months" }\end{array}$ \\
\hline $\begin{array}{l}\text { Scazufca } \\
2009\end{array}$ & 15752089 & Brazil & $\begin{array}{l}\text { No dementia } \\
\text { prevalence data } \\
\text { reported }\end{array}$ & $\begin{array}{l}\text { No prevalence data reported. } \\
\text { Secondary analysis }\end{array}$ \\
\hline $\begin{array}{l}\text { Suemoto } \\
2017\end{array}$ & 15752102 & Brazil & $\begin{array}{l}\text { Non-representative } \\
\text { sample }\end{array}$ & $\begin{array}{l}\text { Participants required an autopsy. } \\
\text { Participants were excluded if } \\
\text { "Subjects with severe chronic }\end{array}$ \\
\hline
\end{tabular}




\begin{tabular}{|c|c|c|c|c|}
\hline & & & & $\begin{array}{l}\text { conditions that might damage } \\
\text { cognitive function prior to death } \\
\text { by interfering in brain } \\
\text { homeostasis. These conditions } \\
\text { include severe heart failure, } \\
\text { chronic kidney failure and } \\
\text { brain metastasis" }\end{array}$ \\
\hline $\begin{array}{c}\text { Vianna } \\
1991\end{array}$ & 13480557 & Brazil & $\begin{array}{l}\text { No formal diagnostic } \\
\text { criteria (with face } \\
\text { validity) applied. }\end{array}$ & $\begin{array}{l}\text { "The IMC [Informação, Memória e } \\
\text { Concentração] was adapted from } \\
\text { Hachinski et al. and tested in } \\
\text { previous work (Viana et al.) } \\
\text { regarding specificity and sensitivity, } \\
\text { with results indicated that this test is } \\
\text { an adequate instrument in the } \\
\text { detection of dementia in the } \\
\text { elderly" (Translation) }\end{array}$ \\
\hline Veras & N020 & Brazil & $\begin{array}{l}\text { No dementia } \\
\text { prevalence reported }\end{array}$ & $\begin{array}{l}\text { The "prevalence of cognitive } \\
\text { impairment" is reported only. }\end{array}$ \\
\hline $\begin{array}{l}\text { Yamada } \\
2002\end{array}$ & 13480562 & Brazil & th-represe & $\begin{array}{l}\text { "The epidemiological study was } \\
\text { done in } 2000 \text { for the Japanese- } \\
\text { Brazilian population in Campo } \\
\text { Grande in Brazil.” }\end{array}$ \\
\hline \multicolumn{5}{|l|}{ India } \\
\hline $\begin{array}{l}\text { Poddar } \\
2011\end{array}$ & & India & $\begin{array}{l}\text { No formal diagnostic } \\
\text { criteria (with face } \\
\text { validity) applied. }\end{array}$ & $\begin{array}{l}\text { "a cut-off score of } \leq 23 \text { was taken to } \\
\text { screen the dementia cases" }\end{array}$ \\
\hline $\begin{array}{l}\text { Raina } \\
2008\end{array}$ & 13480468 & India & $\begin{array}{l}\text { No formal diagnostic } \\
\text { criteria (with face } \\
\text { validity) applied. }\end{array}$ & $\begin{array}{l}\text { "The clinical evaluation was carried } \\
\text { out by a neurologist with the help of } \\
\text { two public health specialists. An } \\
\text { individual was confirmed as a case } \\
\text { of dementia only after the clinical } \\
\text { evaluation which also included a } \\
\text { revisit to cognitive screen scores } \\
\text { (BMSE)." }\end{array}$ \\
\hline
\end{tabular}




\begin{tabular}{|c|c|c|c|c|}
\hline $\begin{array}{l}\text { Riana } \\
2008\end{array}$ & 13480467 & India & $\begin{array}{l}\text { Non-representative } \\
\text { sample. No formal } \\
\text { diagnostic criteria } \\
\text { (with face validity) } \\
\text { applied. }\end{array}$ & $\begin{array}{l}\text { "The prevalence cohort consisted of } \\
200 \text { individuals aged } 60 \text { years and } \\
\text { above residing in the Mishriwala } \\
\text { migrant community cluster of } \\
\text { Jammu city". "An MMSE score } \\
\text { below } 24 \text { (out of a possible score of } \\
\text { 30) was evaluated for clinical } \\
\text { diagnosis. This scoring was } \\
\text { performed to establish the presence } \\
\text { or absence of a dementia syndrome, } \\
\text { stage of severity and the likely } \\
\text { cause." }\end{array}$ \\
\hline $\begin{array}{l}\text { Riana } \\
2010\end{array}$ & 13480465 & India & $\begin{array}{l}\text { No formal diagnostic } \\
\text { criteria (with face } \\
\text { validity) applied. }\end{array}$ & $\begin{array}{l}\text { "The clinical evaluation established } \\
\text { the presence or absense of a } \\
\text { dementia syndrome, its stage of } \\
\text { severity, likely cause and estimated } \\
\text { date of onset....using a standardized } \\
\text { diagnostic protocol" }\end{array}$ \\
\hline Riana & & Ind & $\begin{array}{l}\text { No formal diagnostic } \\
\text { criteria (with face } \\
\text { validity) applied. }\end{array}$ & $\begin{array}{l}\text { "The clinical assessment of } \\
\text { dementia involved a careful detailed } \\
\text { clinical history to determine the } \\
\text { precise features of intellectual loss } \\
\text { if any. The subjects were examined } \\
\text { for three categories of symptoms: } \\
\text { (1) cognitive or intellectual, (2) } \\
\text { functional and (3) psychiatric or } \\
\text { behavioral. An individual was } \\
\text { confirmed as a case of dementia } \\
\text { only after clinical evaluation. The } \\
\text { clinical evaluation also included the } \\
\text { use of cognitive screen scores } \\
\text { (BMSE)." }\end{array}$ \\
\hline $\begin{array}{l}\text { Riana } \\
2014\end{array}$ & 13480463 & India & $\begin{array}{l}\text { No formal diagnostic } \\
\text { criteria (with face } \\
\text { validity) applied. }\end{array}$ & $\begin{array}{l}\text { "The clinical assessment of } \\
\text { dementia involved a careful detailed } \\
\text { clinical history to determine the } \\
\text { precise features of intellectual loss }\end{array}$ \\
\hline
\end{tabular}




\begin{tabular}{|c|c|c|c|c|}
\hline & & & & $\begin{array}{l}\text { if any. The subjects were examined } \\
\text { for three categories of symptoms: } 1 . \\
\text { Cognitive or intellectual, } 2 \text {. } \\
\text { Functional, and, 3. Psychiatric or } \\
\text { behavioural” }\end{array}$ \\
\hline $\begin{array}{l}\text { Saldanha } \\
2010\end{array}$ & 13480487 & India & $\begin{array}{l}\text { Out of date sample } \\
\text { pool }\end{array}$ & $\begin{array}{l}\text { "...based on } 2001 \text { census data" } \\
\text { "total study period of study } \\
\text { extended from July 2005- } \\
\text { September 2007." }\end{array}$ \\
\hline Shaji 2005 & 13480507 & India & Duplicate & $\begin{array}{l}\text { Identified as a duplicate upon } \\
\text { accessing the full-text (13480510) }\end{array}$ \\
\hline $\begin{array}{l}\text { Singh } \\
2008\end{array}$ & 13480516 & India & $\begin{array}{l}\text { No formal diagnostic } \\
\text { criteria (with face } \\
\text { validity) applied. }\end{array}$ & $\begin{array}{l}\text { "Cognitive deficits were assessed by } \\
\text { a separatequestionnaire prepared by } \\
\text { a psychologist, based on existing } \\
\text { questionnaires used in developed } \\
\text { countries. The questionnaire } \\
\text { examined memory function, } \\
\text { intelligence, cognition, and } \\
\text { behaviors of daily life common } \\
\text { among this population" }\end{array}$ \\
\hline \multicolumn{5}{|l|}{ Indonesia } \\
\hline $\begin{array}{c}\text { Hogervorst } \\
2011\end{array}$ & 13480375 & Indonesia & $\begin{array}{l}\text { Out of date sample } \\
\text { pool }\end{array}$ & $\begin{array}{l}\text { "All were over } 56 \text { years of age and } \\
\text { were covered by the local health } \\
\text { districts around Borobudur. Some } \\
\text { were survivors of our earlier study } \\
\text { (Hogervorst, 2008) conducted in } \\
\text { 2006. Of these, an estimated 80\% } \\
\text { could still be contacted for follow- } \\
\text { up from Borobudur and Salam } \\
\text { districts after the } 3 \text { year follow-up in } \\
\text { 2009. Follow-up data are discussed } \\
\text { in another paper, as this paper } \\
\text { concerns the rolling cohort data } \\
\text { collected in 2009, which also }\end{array}$ \\
\hline
\end{tabular}




\begin{tabular}{|c|c|c|c|c|}
\hline & & & & $\begin{array}{l}\text { included novel participants who } \\
\text { were over } 56 \text { years of age in 2009." }\end{array}$ \\
\hline $\begin{array}{c}\text { Suriastini } \\
2017\end{array}$ & N013 & Indonesia & $\begin{array}{l}\text { No formal diagnostic } \\
\text { criteria (with face } \\
\text { validity) applied. }\end{array}$ & $\begin{array}{l}\text { "Subjects were diagnosed with } \\
\text { dementia when } 1 . \text { MMSE score was } \\
\text { below the normative value after } \\
\text { being adjusted for age and } \\
\text { education level (see Supplementary } \\
\text { 1); } 2 \text {. Unable to perform one } \\
\text { activity in IADL; and 3. AD8 score } \\
\text { equal to or higher than 2." }\end{array}$ \\
\hline $\begin{array}{l}\text { Yefusa } \\
2009\end{array}$ & N009 & Indonesia & $\begin{array}{l}\text { Non-representative } \\
\text { sample }\end{array}$ & $\begin{array}{l}\text { "A convenience sample of } 298 \\
\text { elderly was included after giving } \\
\text { informed consent These participants } \\
\text { were attending the local community } \\
\text { health centers, or were visited at the } \\
\text { institute in which they lived ( } \mathrm{n}=49 \text { ) } \\
\text { or at home }(\mathrm{n}=1) \text { " }\end{array}$ \\
\hline \multicolumn{5}{|l|}{ Jamaica } \\
\hline $\begin{array}{l}\text { Waldron } \\
2015\end{array}$ & N018 & & $\begin{array}{l}\text { Dementia prevalence } \\
\text { not reported }\end{array}$ & $\begin{array}{l}\text { "More than one fifth }(21.2 \%, \mathrm{n}= \\
591) \text { of older adults had mild } \\
\text { cognitive impairment and more than } \\
\text { one tenth }(11.0 \%, \mathrm{n}=307) \text { had } \\
\text { severe impairment. The majority } \\
\text { ( } 67.7 \%, \mathrm{n}=1884) \text { of older adults } \\
\text { had no cognitive impairment." }\end{array}$ \\
\hline $\begin{array}{c}\text { Eldemire } \\
1996\end{array}$ & N017 & Jamaica & $\begin{array}{l}\text { Dementia prevalence } \\
\text { not reported }\end{array}$ & $\begin{array}{l}\text { "A community based } \\
\text { study using the Folstein minimental } \\
\text { screening tool identified } 2.3 \% \text { of the } \\
\text { over- } 60 \text { population as severely } \\
\text { impaired and } 11.8 \% \text { as } \\
\text { questionable." }\end{array}$ \\
\hline \multicolumn{5}{|l|}{ Kenya } \\
\hline $\begin{array}{c}\text { Mutiso } \\
2016\end{array}$ & N014 & Kenya & Age of participants & $\begin{array}{l}\text { It is unclear the age of the sample. } \\
\text { No ages were reported. It is unclear } \\
\text { the diagnostic criteria used to }\end{array}$ \\
\hline
\end{tabular}




\begin{tabular}{|c|c|c|c|c|}
\hline & & & $\begin{array}{l}\text { No formal diagnostic } \\
\text { criteria (with face } \\
\text { validity) applied. } \\
\text { Non-representative } \\
\text { sample. }\end{array}$ & $\begin{array}{l}\text { diagnose dementia. It is unclear } \\
\text { whether participants were a } \\
\text { representative sample. }\end{array}$ \\
\hline $\begin{array}{l}\text { Ndetei } \\
2013\end{array}$ & N005 & Kenya & $\begin{array}{l}\text { No formal diagnostic } \\
\text { criteria applied }\end{array}$ & $\begin{array}{l}\text { No clear evidence of diagnostic } \\
\text { criteria applied. However, The } \\
\text { Community Screening Interview for } \\
\text { Dementia was used. }\end{array}$ \\
\hline \multicolumn{5}{|l|}{ Mexico } \\
\hline $\begin{array}{l}\text { Acosta- } \\
\text { Castillo } \\
2017\end{array}$ & 13480273 & Mexico & $\begin{array}{l}\text { No formal diagnost } \\
\text { criteria (with face } \\
\text { validity) applied. }\end{array}$ & $\begin{array}{l}\text { "We developed a dementia } \\
\text { algorithm based on: 1) cognitive } \\
\text { performance evaluated with the } \\
\text { MiniCog, and semantic verbal } \\
\text { fluency, and 2) information about } \\
\text { the basic and instrumental activities } \\
\text { of daily life." Note: Unclear validity } \\
\text { of algorithm. }\end{array}$ \\
\hline $\begin{array}{l}\text { Alanís- } \\
\text { Niño } 2008\end{array}$ & & Mexico & $\begin{array}{l}\text { No formal diagnostic } \\
\text { criteria (with face } \\
\text { validity) applied. }\end{array}$ & $\begin{array}{l}\text { "[The MMSE] is the most used } \\
\text { scale in studies epidemiological } \\
\text { studies to assess deterioration } \\
\text { cognitive and dementia in the } \\
\text { Hispanic population. Several } \\
\text { studies show that it has a good } \\
\text { sensitivity and specificity to identify } \\
\text { cognitive impairment It has been } \\
\text { used to diagnose dementia, } \\
\text { although it's important to consider } \\
\text { the patient's education" } \\
\text { (Translation) }\end{array}$ \\
\hline $\begin{array}{l}\text { Cruz- } \\
\text { Alcala } \\
2002\end{array}$ & N011 & Mexico & $\begin{array}{l}\text { No formal diagnostic } \\
\text { criteria (with face } \\
\text { validity) applied }\end{array}$ & $\begin{array}{l}\text { "Once identified people suspected of } \\
\text { Epilepsy, Vascular Disease } \\
\text { Cerebral, Dementia or Parkinson's } \\
\text { was validated or discarded the }\end{array}$ \\
\hline
\end{tabular}




\begin{tabular}{|c|c|c|c|c|}
\hline & & & & $\begin{array}{l}\text { diagnosis by reviewing clinical files } \\
\text { or with a new interview at home.” } \\
\text { (Translation) }\end{array}$ \\
\hline $\begin{array}{l}\text { Meji- } \\
\text { Arango } \\
2011\end{array}$ & 13480430 & Mexico & $\begin{array}{l}\text { No formal diagnostic } \\
\text { criteria (with face } \\
\text { validity) applied. }\end{array}$ & $\begin{array}{l}\text { "Based on cut-points for the two } \\
\text { instruments all individuals assessed } \\
\text { with the CCCE and the IQCODE } \\
\text { were combined in two global } \\
\text { groups: cognitive normal and } \\
\text { cognitive impaired. Groups were } \\
\text { further classified based on } \\
\text { functional performance. Those who } \\
\text { received help with one or more } \\
\text { basic activities of daily living } \\
\text { (BADLs) and/or two or more } \\
\text { instrumental activities of daily } \\
\text { living (IADLs) were considered } \\
\text { functionally impaired and those who } \\
\text { didn't need help in any activity or } \\
\text { needed help only in one IADL were } \\
\text { considered functionally normal. } \\
\text { Four groups were identified: } 1 \text { ) } \\
\text { Subjects without cognitive } \\
\text { impairment and functionally normal } \\
\text { were the normal group 2) Subjects } \\
\text { functionally impaired and with } \\
\text { normal cognition were named the } \\
\text { FINCI group (for the first letters of } \\
\text { functional impairment not } \\
\text { cognitively impaired). 3) Subjects } \\
\text { with cognitive impairment and no } \\
\text { functional impairment were the } \\
\text { CIND (for the first letters of } \\
\text { cognitive impaired no dementia). 4) } \\
\text { Subjia group.” }\end{array}$ \\
\hline
\end{tabular}




\begin{tabular}{|c|c|c|l|l|}
$\begin{array}{c}\text { Sanchez- } \\
\text { Arenas } \\
2014\end{array}$ & 15752178 & Mexico & $\begin{array}{l}\text { Diagnosis dependent } \\
\text { on accessing service }\end{array}$ & $\begin{array}{l}\text { Sample only included those } \\
\text { "registered with Mexican Institute } \\
\text { of Social Security" }\end{array}$ \\
\hline South Africa & N012 & South \\
Africa & $\begin{array}{l}\text { No formal diagnostic } \\
\text { criteria applied. Non- } \\
\text { representative sample }\end{array}$ & $\begin{array}{l}\text { Diagnosis based on "cognitive } \\
\text { impairment" and "social } \\
\text { impairment". The sample was } \\
\text { composed of "150 randomly } \\
\text { selected Coloured persons aged 65 } \\
\text { years or more” }\end{array}$ \\
\hline
\end{tabular}




\begin{tabular}{|c|c|c|c|c|c|c|c|c|c|c|c|c|c|}
\hline \multirow[t]{2}{*}{ Country } & \multicolumn{2}{|c|}{ Study } & \multicolumn{4}{|c|}{ External Validity } & \multicolumn{6}{|c|}{ Internal Validity } & \multirow{2}{*}{$\begin{array}{c}\text { Summary } \\
\\
\end{array}$} \\
\hline & Author & ID & 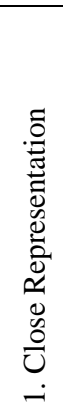 & 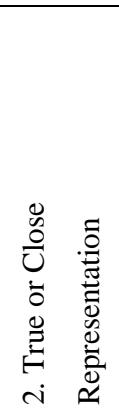 & 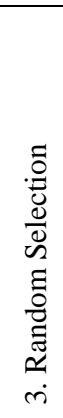 & 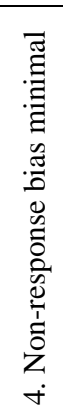 & 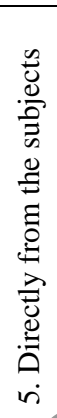 & 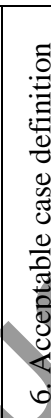 & 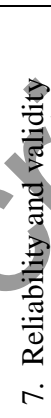 & 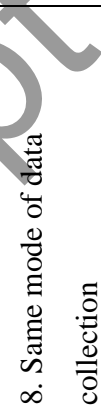 & 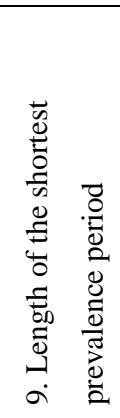 & 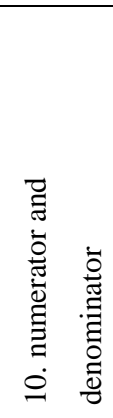 & \\
\hline Brazil & Bottino & 13480301 & $\mathrm{H}$ & $\mathrm{L}$ & $\mathrm{L}$ & $\mathrm{H}$ & L & $\mathrm{L}$ & $\mathrm{L}$ & $\mathrm{L}$ & $\mathrm{L}$ & $\mathrm{L}$ & $\mathrm{M}$ \\
\hline Brazil & Caramelli & 15752121 & $\mathrm{H}$ & $\mathrm{H}$ & $\mathrm{H}$ & $\mathrm{H}$ & & $\mathrm{L}$ & $\mathrm{L}$ & $\mathrm{L}$ & $\mathrm{L}$ & $\mathrm{L}$ & $\mathrm{H}(!)$ \\
\hline Brazil & Cesar & 13480321 & $\mathrm{H}$ & $\mathrm{L}$ & $\mathrm{L}$ & & $\mathrm{L}$ & $\mathrm{L}$ & $\mathrm{L}$ & $\mathrm{L}$ & $\mathrm{L}$ & $\mathrm{L}$ & $\mathrm{H}(!)$ \\
\hline Brazil & Herrera & 15752058 & $\mathrm{H}$ & $\mathrm{L}$ & & $\mathrm{L}$ & $\mathrm{L}$ & $\mathrm{L}$ & $\mathrm{L}$ & $\mathrm{L}$ & $\mathrm{L}$ & $\mathrm{L}$ & $\mathrm{L}$ \\
\hline Brazil & Lopes & 13480416 & $\mathrm{H}$ & $\mathrm{L}$ & & $\mathrm{H}$ & $\mathrm{L}$ & $\mathrm{L}$ & $\mathrm{L}$ & $\mathrm{L}$ & $\mathrm{L}$ & $\mathrm{L}$ & $\mathrm{H}$ \\
\hline Brazil & Magalhaes & 15752146 & $\mathrm{H}$ & & $\mathrm{L}$ & $\mathrm{L}$ & $\mathrm{L}$ & $\mathrm{H}$ & $\mathrm{L}$ & $\mathrm{L}$ & $\mathrm{L}$ & $\mathrm{L}$ & $\mathrm{H}(!)$ \\
\hline Brazil & Scazufca & 13480493 & $\mathrm{H}$ & & $\mathrm{L}$ & $\mathrm{L}$ & $\mathrm{L}$ & $\mathrm{L}$ & $\mathrm{L}$ & $\mathrm{L}$ & $\mathrm{L}$ & $\mathrm{L}$ & $\mathrm{L}$ \\
\hline India & Banerjee & 8545180 & & $\mathrm{H}$ & $\mathrm{L}$ & $\mathrm{H}$ & $\mathrm{L}$ & $\mathrm{L}$ & $\mathrm{L}$ & $\mathrm{L}$ & $\mathrm{L}$ & $\mathrm{L}$ & $\mathrm{H}$ \\
\hline India & Banerjee & 13480294 & $\mathrm{H}$ & $\mathrm{L}$ & $\mathrm{L}$ & $\mathrm{H}$ & $\mathrm{L}$ & $\mathrm{L}$ & $\mathrm{L}$ & $\mathrm{L}$ & $\mathrm{L}$ & $\mathrm{L}$ & $\mathrm{M}$ \\
\hline India & Chandra & 13480326 & $\mathrm{H}$ & $\mathrm{L}$ & $\mathrm{L}$ & $\mathrm{L}$ & $\mathrm{L}$ & $\mathrm{L}$ & $\mathrm{L}$ & $\mathrm{L}$ & $\mathrm{L}$ & $\mathrm{L}$ & $\mathrm{L}$ \\
\hline
\end{tabular}




\begin{tabular}{|c|c|c|c|c|c|c|c|c|c|c|c|c|c|}
\hline India & Das & 15752010 & $\mathrm{H}$ & $\mathrm{L}$ & $\mathrm{L}$ & $\mathrm{L}$ & $\mathrm{L}$ & $\mathrm{L}$ & $\mathrm{L}$ & $\mathrm{L}$ & $\mathrm{L}$ & $\mathrm{H}$ & $\mathrm{L}$ \\
\hline India & Gurukartick & 13480366 & $\mathrm{H}$ & $\mathrm{L}$ & $\mathrm{L}$ & $\mathrm{H}$ & $\mathrm{L}$ & $\mathrm{L}$ & $\mathrm{L}$ & $I$ & $\mathrm{~L}$ & $\mathrm{~L}$ & $\mathrm{M}$ \\
\hline India & Jacob & 13480387* & $\mathrm{H}$ & $\mathrm{H}$ & $\mathrm{L}$ & $\mathrm{L}$ & $\mathrm{L}$ & $\mathrm{L}$ & $\mathrm{L}$ & $\mathrm{L}$ & $\mathrm{L}$ & $\mathrm{L}$ & $\mathrm{M}$ \\
\hline India & Mathuranath & 13480423 & $\mathrm{H}$ & $\mathrm{L}$ & $\mathrm{L}$ & $\mathrm{L}$ & $\mathrm{L}$ & $\mathrm{L}$ & & L & $\mathrm{L}$ & $\mathrm{L}$ & M \\
\hline India & Rajkumar & 13480469 & $\mathrm{H}$ & $\mathrm{L}$ & $\mathrm{L}$ & $\mathrm{L}$ & $\mathrm{L}$ & & $\mathrm{L}$ & $\mathrm{L}$ & $\mathrm{L}$ & $\mathrm{L}$ & $\mathrm{L}$ \\
\hline India & Rodriguez & $13480477 *$ & $\mathrm{H}$ & $\mathrm{H}$ & $\mathrm{L}$ & $\mathrm{H}$ & $\mathrm{L}$ & L & $\mathrm{L}$ & $\mathrm{L}$ & $\mathrm{L}$ & $\mathrm{L}$ & $\mathrm{H}$ \\
\hline India & Seby & N010 & $\mathrm{H}$ & $\mathrm{H}$ & $\mathrm{L}$ & $\mathrm{L}$ & L & $\mathrm{L}$ & $\mathrm{L}$ & $\mathrm{L}$ & $\mathrm{L}$ & $\mathrm{L}$ & $\mathrm{M}$ \\
\hline India & Shaji & 13480510 & $\mathrm{H}$ & $\mathrm{H}$ & $\mathrm{L}$ & & $\mathrm{L}$ & $\mathrm{L}$ & $\mathrm{L}$ & $\mathrm{L}$ & $\mathrm{L}$ & $\mathrm{L}$ & $\mathrm{M}$ \\
\hline India & Shaji & 13480511 & $\mathrm{H}$ & $\mathrm{H}$ & $\mathrm{L}$ & & $\mathrm{L}$ & $\mathrm{L}$ & $\mathrm{L}$ & $\mathrm{L}$ & $\mathrm{L}$ & $\mathrm{L}$ & M \\
\hline India & Singh & 13480516 & $\mathrm{H}$ & $\mathrm{L}$ & $\mathrm{H}$ & $\mathrm{H}$ & $\mathrm{L}$ & $\mathrm{L}$ & $\mathrm{L}$ & $\mathrm{L}$ & $\mathrm{L}$ & $\mathrm{H}$ & $\mathrm{H}$ \\
\hline India & Tiwari & 15752131 & $\mathrm{H}$ & $\mathrm{H}$ & & $\mathrm{L}$ & $\mathrm{L}$ & $\mathrm{L}$ & $\mathrm{L}$ & $\mathrm{L}$ & $\mathrm{L}$ & $\mathrm{L}$ & M \\
\hline India & Vas & 13480548 & $\mathrm{H}$ & 1 & $\mathrm{~L}$ & $\mathrm{~L}$ & $\mathrm{~L}$ & $\mathrm{~L}$ & $\mathrm{~L}$ & $\mathrm{~L}$ & $\mathrm{~L}$ & $\mathrm{H}$ & M \\
\hline Jamaica & $\begin{array}{l}\text { Eldemire- } \\
\text { Shearer }\end{array}$ & 157520466 & & I & $\mathrm{H}$ & $\mathrm{H}$ & $\mathrm{L}$ & $\mathrm{L}$ & $\mathrm{L}$ & $\mathrm{L}$ & $\mathrm{L}$ & $\mathrm{L}$ & M \\
\hline Jamaica & Neita & 13480438 & $\mathrm{H}$ & $\mathrm{H}$ & $\mathrm{L}$ & $\mathrm{H}$ & $\mathrm{L}$ & $\mathrm{L}$ & $\mathrm{L}$ & $\mathrm{L}$ & $\mathrm{L}$ & $\mathrm{L}$ & $\mathrm{H}$ \\
\hline Mexico & Rodriguez & $13480477^{*}$ & $\mathrm{H}$ & $\mathrm{H}$ & $\mathrm{L}$ & $\mathrm{L}$ & $\mathrm{L}$ & $\mathrm{L}$ & $\mathrm{L}$ & $\mathrm{L}$ & $\mathrm{L}$ & $\mathrm{H}$ & $\mathrm{M}$ \\
\hline
\end{tabular}




\begin{tabular}{|l|l|l|l|l|l|l|l|l|l|l|l|l|l|}
\hline Mexico & Cruz Alcala & N016 & H & L & L & L & L & L & H & L & L & H & L \\
\hline Mexico & $\begin{array}{l}\text { Velázquez- } \\
\text { Brizuela }\end{array}$ & 13480552 & H & L & L & H & L & L & L & L & L & L & M \\
\hline $\begin{array}{l}\text { South } \\
\text { Africa }\end{array}$ & Van der Poel & $113480542 *$ & H & H & H & L & H & L & H & L & L & H & H \\
\hline $\begin{array}{l}\text { South } \\
\text { Africa }\end{array}$ & De Jaegar & 13480339 & H & H & H & H & L & L & L & L & L & L & H \\
\hline * The study is part of the 10/66 group, (!) Studies with a very high dementia prevalence rate >15\%. & & & & & \\
\hline
\end{tabular}

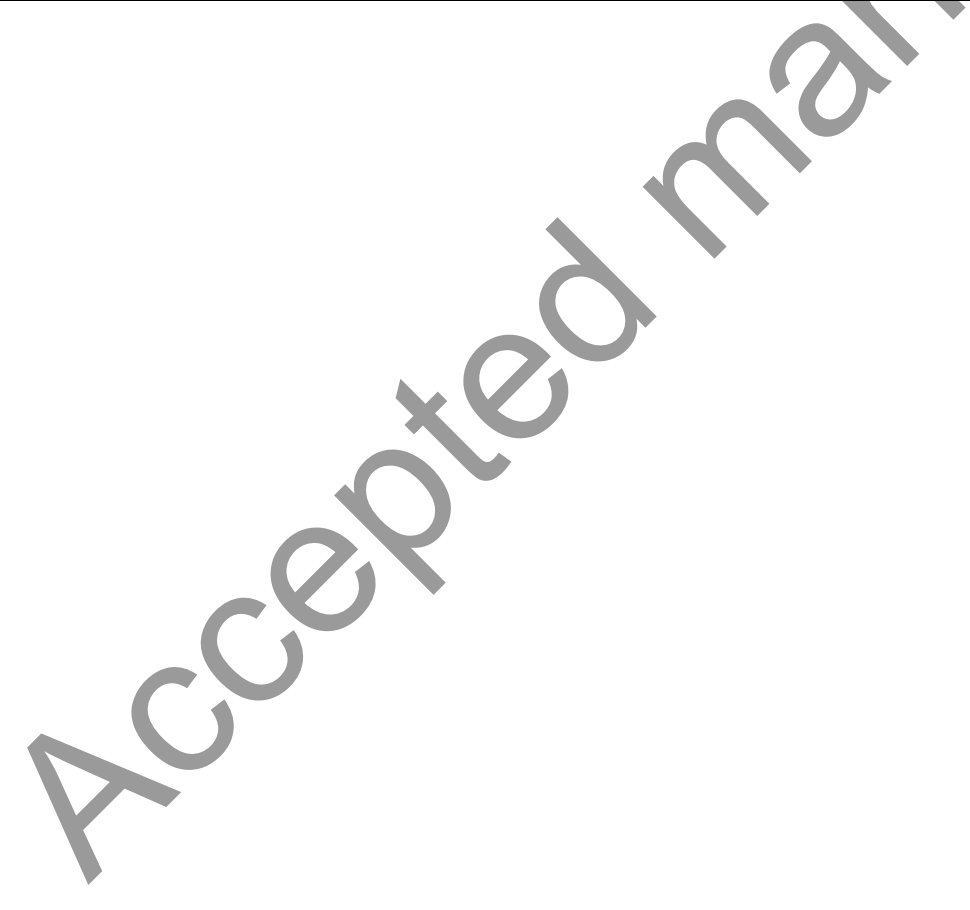

